\title{
O OUTRO LADO DA MOEDA: estimativas e impactos do ouro do Brasil no tráfico transatlântico de escravos (Costa da Mina, c. 1700-1750)
}

\author{
Gustavo Acioli Lopes* \\ Leonardo Marques**
}

\begin{abstract}
RESUMO: Uma ampla historiografia relacionou as descobertas do ouro no Brasil ao aumento na demanda por mão de obra africana forçada, o que, por sua vez, levou a uma intensificação das atividades de negreiros luso-brasileiros na Costa da Mina. Ainda são poucas as pesquisas, no entanto, que consideram o papel do ouro nas trocas diretas por escravos no Golfo de Benim e Costa do Ouro. Com base em dados quantitativos e qualitativos, este artigo oferece uma estimativa do volume de ouro levado do Brasil para a Costa da Mina e avalia a sua importância para a aquisição de escravizados naquela área pelos luso-brasileiros.

PALAVRAS-CHAVE: Ouro; Tráfico de escravos; Impérios atlânticos; Minas Gerais; Costa da Mina.
\end{abstract}

\section{The Other Side of the Coin: Estimates and Impacts of Brazilian Gold on the Transatlantic Slave Trade (Costa da Mina, c. 1700-1750)}

ABSTRACT: Historians have shown how the discoveries of gold in Brazil led to a rise in the demand for African labor, which in turn led to a stronger presence of Luso-Brazilian slave traders at the Mina Coast. However, few works have explored the specific role of gold in slave-trading activities in the Bight of Benin. Based on quantitative and qualitative data, this article offers an estimate of gold exports to the Mina Coast and analyzes its role in the slave-trading transactions involving LusoBrazilians in that region.

KEYWORDS: Gold; Slave trade; Atlantic empires; Minas Gerais; Costa da Mina.

\section{La otra cara de la moneda: estimaciones e impactos del oro de Brasil en el tráfico transatlántico de esclavos (Costa da Mina, c. 1700-1750)}

RESUMEN: Una amplia producción historiográfica ha relacionado el descubrimiento de minas de oro en Brasil con el aumento en la demanda de mano de obra africana forzada que llevó, a su vez, a una intensificación de las actividades de traficantes de esclavos luso-brasileños en la Costa da Mina, región de África occidental. Sin embargo, todavía son pocas las investigaciones que consideran el rol cumplido por el oro y su intercambio directo por esclavos en el Golfo de Benín. Utilizando informaciones cuantitativas y cualitativas, este artículo ofrece una estimativa del volumen de oro llevado desde Brasil a la Costa da Mina, así como evalúa su importancia para la adquisición de personas esclavizadas por los luso-brasileños en aquella zona.

PALABRAS CLAVE: Oro; Trata de esclavos; Imperios atlánticos; Minas Gerais; Costa da Mina.

\footnotetext{
*Doutor em História Econômica pela Universidade de São Paulo. Atualmente, é professor de História Econômica do departamento de História da Universidade Federal Rural de Pernambuco. Contato: Rua Dom Manuel de Medeiros, s/n, Dois Irmãos, CEP: 52171-900, Recife-PE, Brasil. E-mail: gustavo.acioli@ufrpe.br. ORCID: http://orcid.org/0000-0001-9769-9054.
}

\footnotetext{
**Doutor em História pela Emory University (Estados Unidos). Atualmente, é professor de História da América Colonial no Instituto de História da Universidade Federal Fluminense. Contato: Rua Prof. Marcos Waldemar de Freitas Reis, Bloco O, sala 507, CEP: 24210-201, Niterói-RJ, Brasil. E-mail: 1m@id.uff.br. ORCID: http://orcid.org/0000-0003-1276-2769.
} 
Em princípios do século XVIII, Antonil estimava que menos de um terço do ouro extraído do Brasil era declarado às autoridades portuguesas; Felix Madureira e Gusmão, seu contemporâneo, acreditava que esse valor, na verdade, era de menos de um décimo. Para o historiador Charles Boxer, apenas a segunda estimativa poderia ser vista como exagerada. Mais maleável e valioso do que a prata, o ouro foi contrabandeado em larga escala ao longo da história colonial das Américas. Ainda assim, Virgílio Noya Pinto, Michel Morineau e outros historiadores avançaram significativamente nas discussões sobre os números da produção aurífera no Brasil setecentista. A estimativa total da produção brasileira de 876.629 quilos de ouro oferecida por Noya Pinto para o século XVIII é uma das mais amplamente utilizadas, não muito distante do número oferecido por Pandiá Calógeras, que, diferentemente daquele, incluiu a Bahia em seus cálculos: 948.105 quilos. O auge dessa produção se deu em meados do setecentos, entrando em declínio mais acentuado nas últimas três décadas do século. ${ }^{1}$

Para onde foi todo esse ouro? Se a historiografia produziu excelentes discussões em torno dos números totais da produção aurífera brasileira, a questão adjacente sobre seus destinos ainda está longe de ser esgotada. Análises da relação entre o ouro do Brasil e a Europa, com especial atenção para a Grã-Bretanha, vão de Werner Sombart a Pierre Vilar, passando por Roberto Simonsen e Celso Furtado, e culminando com os trabalhos fundamentais de H.E.S. Fisher e Sandro Sideri na década de $1970 .^{2}$ Para saldar o déficit de sua balança com a Inglaterra, Portugal era obrigado a remeter ouro àquele reino, situação que D. Luís da Cunha lamentava em suas Instruções, afirmando que o ouro do Brasil, "em barra ou moeda, (...) na Inglaterra corre como se fosse natural," isto é, como se fosse do próprio país. Além disso, prosseguia Cunha, "sempre estaremos dependentes de Inglaterra, que tem Portugal pela melhor das suas colônias, pois lhe dá o ouro e os diamantes, que lhe não produz as que ela possui". ${ }^{3}$ Assim, as limitações da produção portuguesa de manufaturas, particularmente têxteis, bem como seu acesso restrito às fazendas da Índia, faziam com que Portugal tivesse que importá-las do Noroeste europeu (sobretudo da Inglaterra). Dados precisos do volume de ouro drenado pela Grã-Bretanha no século XVIII não existem, mas David Richardson e E.W. Evans sugerem que um total de 50 milhões de libras esterlinas não é um número irrealista. ${ }^{4}$

A grande maioria desses trabalhos tem pouco a dizer sobre a África. O livro de Noya Pinto, por exemplo, traz pouquíssimas considerações sobre o fluxo de ouro do Brasil para o continente africano. Apesar de algumas referências ao papel do ouro no trato negreiro, o autor 
não faz qualquer referência a tais fluxos quando elenca os descaminhos do contrabando do ouro ou quando discute o tráfico de escravos mais a fundo. O livro de H.E.S. Fisher, por sua vez, menciona a importância do tráfico de escravos britânico para a América espanhola como forma de acessar a prata, bem como o uso de navios britânicos por portugueses no comércio com a Madeira, Açores e Cabo Verde, mas também não traz qualquer discussão sobre o comércio anglo-português de escravos na África. Em artigo mais recente, no qual analisa o contrabando de ouro e de farinha de mandioca, Christopher Ebert elabora uma discussão sobre a África apenas quando trata do segundo item. O trabalho de Leonor Freire Costa, Maria Manuela Rocha e Rita Martins de Sousa tampouco faz qualquer referência ao tema. ${ }^{5}$

O ouro do Brasil, no entanto, foi um dos principais instrumentos a permitir a expansão do comércio de escravos por luso-brasileiros na Costa da Mina, região que, como notavam os contemporâneos, foi uma das mais importantes fontes de escravos para a América portuguesa no setecentos. ${ }^{6}$ Uma ampla historiografia, iniciada com os trabalhos de Luiz Viana Filho e Maurício Goulart, e aprofundada por Pierre Verger e outros historiadores mais recentes, demonstrou a força dos laços entre a Costa da Mina e a América portuguesa, com escravos oriundos daquela região ocupando um papel central nesta, especialmente nas zonas mineradoras. ${ }^{7}$ Uma vez na África, os destinos do ouro do Brasil foram diversos. Parte seguiu para a Europa nas mãos de comerciantes europeus, em especial holandeses, franceses e britânicos. Outra parte permaneceu na própria África Ocidental. Um dos grandes consumidores de ouro brasileiro, por exemplo, era o rei do Daomé, Agaja, que a partir dos anos 1720 passou a privilegiar comerciantes vindos do Brasil. Comerciantes britânicos, franceses e holandeses em Uidá, ávidos por novos suprimentos de africanos escravizados, atribuíam os baixos números à conexão direta estabelecida entre Agaja e os traficantes portugueses. A oeste, na Costa do Ouro, região tradicionalmente voltada à exportação do metal amarelo, a ascensão dos Axante em princípios do XVIII foi igualmente marcada por uma crescente demanda por ouro (que já não podia mais ser suprida internamente). ${ }^{8}$

As exportações de ouro do Brasil, portanto, alimentaram não apenas a avassaladora demanda de uma Europa em expansão, mas também as expectativas de diferentes sociedades africanas na Costa da Mina. A extração do ouro no Brasil, por sua vez, gerou uma demanda por trabalho na colônia em escala inaudita, que foi suprida, em grande medida, por escravos da África Ocidental. Estes cativos foram trocados pelo ouro que havia sido extraído por outros escravos, anteriormente carregados para aquelas mesmas regiões do interior do Brasil. Fosse para ser usado como dinheiro na África Ocidental ou na Europa, a demanda pelo metal 
amarelo transformou a América portuguesa, aprofundando a fronteira escravista no interior da colônia e integrando de modo mais consistente a economia colonial do Norte ao Sul. A exportação do ouro extraído no interior também estimulou uma série de desenvolvimentos políticos e econômicos na África Ocidental e na Europa setentrional, além de permitir que se fechassem os circuitos globais que articularam a Ásia ao Atlântico. O presente artigo explora as conexões trans-imperiais do trato negreiro na Costa da Mina e oferece estimativas para o volume de ouro brasileiro que seguiu para a África na primeira metade do século XVIII, momento de auge da produção aurífera do Brasil, bem como do trato negreiro conduzido por portugueses na Costa da Mina. Dessa forma, além de melhor avaliar o papel do ouro (frente a outros "gêneros da terra") neste segmento do trato escravista, pretendemos contribuir para os esforços de incorporação do sistema atlântico ibérico, especialmente sua face portuguesa, nas discussões em torno da trajetória do capitalismo enquanto sistema histórico.

\section{A reconstrução do trato negreiro português na África Ocidental}

Metais preciosos foram componentes fundamentais da expansão europeia ultramarina em princípios da era moderna. Como demonstrou Vitorino Magalhães Godinho em trabalho pioneiro, o ouro foi um dos motores fundamentais da expansão portuguesa pela costa ocidental da África, eventualmente permitindo a expansão das trocas comerciais oceano Índico adentro. ${ }^{9}$ A descoberta da América, por sua vez, intensificou os fluxos globais de ouro, inicialmente por meio da pilhagem de populações indígenas do Caribe e do continente; depois, pela exploração do trabalho de africanos escravizados, especialmente na região de Nova Granada (atual Colômbia). A África prosseguiu sendo uma importante fornecedora de ouro, responsável por $35 \%$ do volume importado pela Europa no XVI e $22 \%$ no século seguinte. ${ }^{10}$ No entanto, particularmente importante para a formação de uma economia mundial foi a descoberta de enormes reservas de prata na América. O metal branco formava a base das economias da China e, parcialmente, da Índia, o que, consequentemente, levou a uma enorme demanda pelo produto nas duas regiões ${ }^{11}$. Não por acaso, o processo inicial de conquista de Angola tinha como uma de suas motivações centrais a busca por reservas de prata, expectativa que rapidamente se revelou ilusória. As grandes fontes de prata que tornaram possível a construção desse comércio global no longo século XVI estavam do outro lado do Atlântico, em especial nos Andes. Potosí permitiu não apenas a construção dos fluxos comerciais globais, mas também uma série de transformações na própria Europa, com Antuérpia e, 
posteriormente, Amsterdã emergindo como principais centros financeiros do Velho Mundo. ${ }^{12}$

A chamada crise do século XVII esteve diretamente ligada ao declínio dos fluxos de prata para a Europa, a despeito da "conjuntura oposta" que marcou a América espanhola, em especial a Nova Espanha, durante aquele mesmo período. ${ }^{13}$ Se a escassez de metais preciosos se acentuava na Europa da segunda metade do seiscentos, tal situação era agravada no caso português. A expansão holandesa havia levado à perda de inúmeros entrepostos portugueses na Ásia enquanto o fim da União Ibérica (e, consequentemente, da concessão do asiento aos portugueses) dificultou o acesso à prata por comerciantes lusos. Além disso, a guerra contra os holandeses em Pernambuco e a destruição deixada em seu rastro drenou recursos significativos, situação que foi complicada pela ascensão de concorrentes no Caribe, em especial Barbados, que em fins do XVII havia se tornado uma das principais produtoras de açúcar do planeta. ${ }^{14}$

Foi nesse contexto, de escassez de metais preciosos e surgimento de colônias rivais no Caribe, que a Coroa portuguesa estimulou novas buscas por metais preciosos no interior da América Portuguesa, colônia que havia se tornado muito mais central para o império português após a perda de entrepostos asiáticos para os holandeses na primeira metade do século XVII. Na última década do século, aumentavam as notícias em torno de grandes reservas de ouro sendo descobertas na região de Minas Gerais, seguidas por Goiás e Mato Grosso nas décadas seguintes. Tais descobertas transformaram significativamente a colônia, gerando uma demanda por trabalho forçado que, combinada com as necessidades da produção açucareira e de outros setores produtivos, elevou a participação portuguesa no tráfico transatlântico de escravos a um novo patamar. ${ }^{15}$ As descobertas auríferas tiveram impactos diversos sobre as regiões do Brasil: afetaram a produção açucareira nas capitanias do Norte e na Bahia, uma vez que a elevada demanda e capacidade de importação do centro-sul pressionaram para cima os preços dos escravizados de origem africana importados pelos portos da costa Nordeste e Sudeste do Brasil. ${ }^{16} \mathrm{O}$ centro-sul, por sua vez, em particular o Rio de Janeiro e as Minas Gerais, passou a ser o principal destino dos africanos escravizados na América portuguesa. ${ }^{17}$ Nas primeiras três décadas do setecentos, os portos da Bahia e de Pernambuco participaram ativamente do fornecimento de cativos à região das Minas, fosse desembarcando-os no porto do Rio, fosse remetendo-os por terra, pelo caminho do sertão, o que, somando-se à oferta de diversos gêneros, estreitou a articulação mercantil entre o Norte e o Sul da América portuguesa. ${ }^{18}$ No entanto, aqueles desembarcadouros foram superados pelo porto fluminense a partir da década de 1730, quando passaria a ser o maior centro de 
comércio escravista do Brasil e o maior das Américas até o século XIX (exceto na década de 1780, quando Saint Domingue ultrapassou todos ). ${ }^{19}$

Dos cativos desembarcados no Brasil e, particularmente, na Bahia e no Rio de Janeiro, entre 1701 e 1730, a grande maioria provinha da África Ocidental ou, mais precisamente, da Costa da Mina. ${ }^{20}$ Não apenas os números de desembarque comprovam a superioridade numérica dos "minas" frentes aos "angolas", mas dados oriundos de inventários, registros de batismos e matrículas de escravos confirmam o predomínio de homens, mulheres e crianças embarcados no Golfo de Benin entre os escravos da região das Minas e da Bahia. ${ }^{21}$ Embora historiadores tenham destacado, não sem fundamento, o papel dos produtos da terra, em especial o tabaco, na ascensão do comércio negreiro do Nordeste do Brasil com a Costa da Mina, argumentamos que as descobertas e o constante aumento da produção aurífera foram um componente fundamental da consolidação dessa rota escravista. Efetivamente, há registros da navegação da Bahia e Pernambuco para o Golfo de Benin desde os anos 1660, mas, com frequência modesta, como atesta um testemunho dos anos 1680: "athe o prezente vinhão a esta Ilha [São Tomé] alguns navios do Brazil q com os ditos direitos q pagavão se satisfazião os soldados, aos governadores" e o que sobrava pagava os soldados da fortaleza. Porém, "como os ditos Navios faltarão de pancada, pelos poucos lucros que tiravão da costa", a alfândega ficara sem rendimento. ${ }^{22}$ Bastou, no entanto, que o ouro começasse a ser desentranhado das Gerais para a situação mudar. Dizia, em 1699, a câmara de São Tomé "que esta alfandega [tem] há dous annos dobrados rendimentos pellos muitos navios que do brazil vem despachar escravos". 23

O papel central do ouro na aquisição de cativos "minas" nesse período é indicado por testemunhos contemporâneos, como o de um governador da Paraíba, que, ao se referir às dificuldades enfrentadas pelos negreiros daquela capitania no mercado atlântico, afirmava que, na Costa da Mina, "se achavão differentes embarcaçoenz da Bahia, Pernambuco e Rio de Janeiro, fazendo o mesmo negócio [a compra de cativos] a troco de ouro em pó e em moeda, com tanta soltura e largura" que a sumaca da Paraíba só conseguiu adquirir, com os "gêneros da terra" [leia-se, principalmente, tabaco], 60 escravos, embora sua arqueação fosse de $240 .{ }^{24}$

Ainda que negreiros de Portugal frequentassem a "costa de Aladá" desde fins do XVI e os de Pernambuco e da Bahia já se fizessem presentes na Costa da Mina em meados do XVII, este fluxo adensou-se apenas no último quarto do Seiscentos. ${ }^{25} \mathrm{Se}$, neste período, o tabaco baiano e pernambucano foi o principal item a permitir aos negreiros do Brasil uma inserção favorável no comércio da região, ainda dominado por Aladá, no início da centúria 
seguinte o metal amarelo tornava-se cada vez mais presente nestas transações. ${ }^{26}$ Aliás, devese à atração do ouro a renovada presença de embarcações saídas de Lisboa fazendo comércio na Costa da Mina e, daí, para o Brasil; entre 1701-1730, a média de viagens nesta rota mais que triplica, o que pode ser entendido, também, como uma das vias pela quais os mercadores reinóis buscavam ter acesso ao ouro do Brasil. $^{27}$

Paralelamente, o comércio de escravos realizado pelos súditos ingleses e franceses também conheceu um novo impulso, aumentando exponencialmente o seu volume na virada do século. Ao longo do setecentos, plantations caribenhas estabelecidas por poderes do noroeste europeu atingiram sua maturidade produtiva no mercado de açúcar, tabaco e, posteriormente, café, produtos que, paulatinamente, passariam a fazer parte da cesta de consumo das pessoas comuns da Europa ocidental. ${ }^{28}$ Diante dessa enorme demanda, companhias monopolistas tradicionais se mostraram incapazes de suprir números satisfatórios de cativos para as plantations. No caso inglês, o monopólio do comércio escravista nas costas africanas cederia espaço ao avanço de mercadores privados (os entrelopos e, posteriormente, os ten percenters), que elevariam o volume de cativos deportados sob a bandeira inglesa para a América a novos patamares. ${ }^{29}$

Na Costa da Mina, no entanto, nenhum Estado ou companhia de comércio sancionada por um poder estatal tinha domínio territorial, apesar de ingleses, franceses, holandeses e, em bem menor medida, portugueses terem estabelecido um cluster escravista na região, construindo vários fortes e feitorias, ainda que não tantos quanto os que ergueram na Costa do Ouro. Assim, não era possível excluir nenhum dos concorrentes do comércio de escravos em Uidá ou nos demais portos. ${ }^{30}$ Igualmente, as autoridades locais evitavam sistematicamente negociar com apenas uma das nações representadas pelos diversos agentes europeus enviados para ou atuando na região. ${ }^{31}$ Portanto, se o comércio na Costa da Mina não era exatamente um mercado livre, era bastante competitivo e a oferta e obtenção de cativos dependiam da capacidade de ofertar os bens adequados a preços compatíveis com as expectativas dos mercadores locais. ${ }^{32}$ Enquanto a demanda americana por trabalho africano aumentou substancialmente a partir de fins do século XVII, o papel desempenhado pela Costa da Mina na exportação de escravos se acentuou no mesmo período. Entre 1700-1730, as exportações da Costa da Mina atingiram seu primeiro pico, quase dobrando em volume. ${ }^{33}$ Para tanto, contribuíram tanto fatores do lado da demanda, quanto da oferta. De um lado, agentes mercantis de outras nações europeias, além de Portugal e Holanda, começaram a traficar naquela região, principalmente ingleses e franceses. O volume das exportações de africanos 
escravizados por ingleses foi ainda maior do que se supunha, mas os franceses ganharam relevância no tráfico, efetivamente, em torno de 1710, concentrando a maior parte da sua mercancia escravista na África Ocidental, incluindo a baía de Benin. ${ }^{34}$

Por sua vez, do lado dos fornecedores de escravos no Golfo do Benin, a oferta de cativos tornou-se mais regular entre 1650 e 1690, uma vez que o sistema de escravização desenvolvido pelos agentes locais do tráfico (oficiais ou particulares) atingiu um ponto de "maturidade". ${ }^{35} \mathrm{O}$ aumento acentuado na demanda atlântica por escravos fez-se sentir na Costa dos Escravos e na Costa do Ouro, que passaram a suportar a maior drenagem de braços pelo tráfico transatlântico. Aquela região vinha emergindo como exportadora de mão-de-obra cativa da África Ocidental desde décadas anteriores, mas o ponto de viragem ocorreu, de fato, nos anos 1690. Em parte, pelo declínio das exportações de metal precioso da Costa do Ouro (que havia atraído os europeus para a região desde o século XV), que caíram pela metade naquela década. De exportadora de ouro a região passou a importadora. De importadora de escravos passou a exportadora, com o volume total de cativos exportados entre 1700 e 1740 atingindo um volume quatro vezes superior ao que havia sido nos 40 anos anteriores. Já a Costa dos Escravos e a Baía de Benin tornaram-se as maiores exportadoras de escravos, entre 1662-1713, com 50\% do total da África Ocidental. ${ }^{36}$ Quando comparamos o último quartel do século XVII aos vinte e cinco anos seguintes, o número de cativos embarcados na Costa da Mina quase dobrou, sendo Salvador o principal porto do Brasil nesta rota, responsável por $34 \%$ e $48 \%$ dos embarques, nos respectivos períodos. Embora o número de escravizados saídos daquela Costa tenha permanecido estável (com ligeiro aumento) no segundo quarto do setecentos, a participação baiana subiu para $51 \%$, enquanto a de Pernambuco foi de $4 \%$ a $10 \%$, ou seja, o Brasil tornou-se o destino de mais da metade dos cativos da "Mina".37

A relação estreita entre as descobertas do ouro em Minas Gerais e a consolidação do tráfico português na Costa da Mina fica evidente no Gráfico 1. Um certo declínio do tráfico na região ocorreu pouco antes do início do declínio do ouro, em grande medida por causa de turbulências em toda a Costa da Mina nos anos 1740. No caso da Costa do Ouro, a atividade de negreiros luso-brasileiros vinha em declínio desde os anos 1730, como consequência de sua consolidação na Costa dos Escravos. Para a maioria desses traficantes, Elmina tornou-se, acima de tudo, um entreposto para a aquisição de cauris e tecidos, que eram trocados por escravos no Golfo do Benim. ${ }^{38}$ A Costa dos Escravos, por sua vez, passou por turbulências significativas na década de 1740, principalmente a retomada da guerra entre o reino de Daomé 
Gráfico 1: Volume total de ouro extraído do Brasil e de escravos embarcados na Costa da Mina, 1681-1770

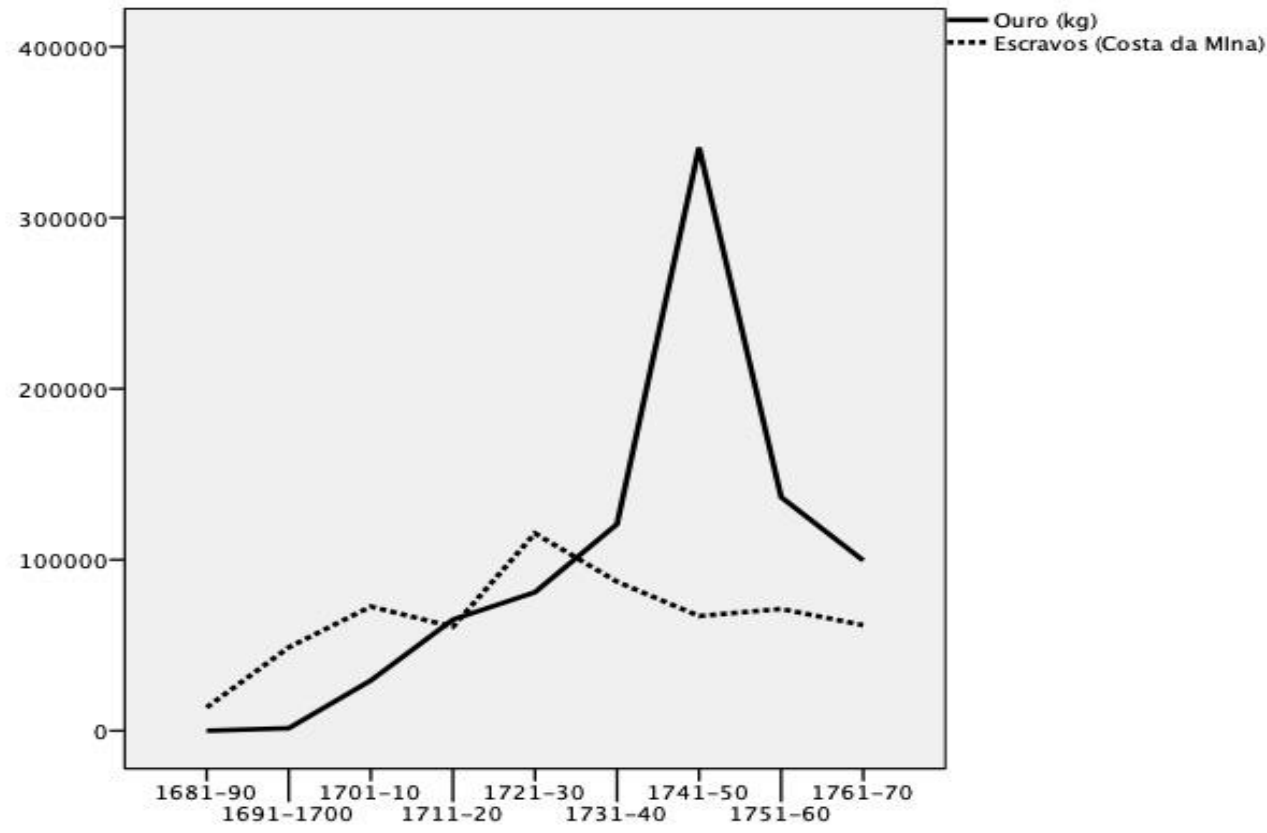

Fonte: Estimativas de extração do ouro de PINTO, Virgílio Noya. O ouro brasileiro e o comércio anglo-português: uma contribuição dos estudos da economia atlântica no século XVIII. 2. ed ed. São Paulo: Ed. Nacional, 1979. Estimativas de embarques de escravizados em www.slavevoyages.org Consultado em 29/07/2019.

e o império Oyo, levando a uma grande oscilação no trato negreiro. Em 1739 e 1743, por exemplo, o rei do Daomé ordenou a prisão de João Basílio, diretor do forte português Ajudá, sob a acusação de que este apoiava seus inimigos e prejudicava o comércio. A oscilação no trato negreiro na Costa da Mina era complementada pela consolidação de Angola, cujo papel fundamental enquanto fonte de cativos para o Brasil se acentuava ainda mais com a ascensão do Rio de Janeiro na segunda metade do setecentos. ${ }^{39}$

\section{As múltiplas demandas por ouro}

Com o afluxo de ouro brasileiro na Costa da Mina, embarcado pelos mercadores de almas do Rio de Janeiro, Pernambuco e, principalmente, da Bahia ${ }^{40}$, tornam-se mais recorrentes as relações mercantis entre estes negreiros e os demais, em particular com ingleses, holandeses e franceses. ${ }^{41}$ Embora as relações entre luso-brasileiros e demais europeus na Costa da Mina tenham ido além das exações que os holandeses obtinham dos súditos portugueses na região, depois das disputas luso-holandesas na África terminarem num "empate", as trocas mercantis passaram ao primeiro plano apenas com a introdução do ouro 
brasileiro no conjunto de bens carreados para a Costa da Mina. ${ }^{42}$ A partir de então, não apenas os holandeses passaram a estreitar os laços mercantis com os luso-brasileiros (sem que as hostilidades, no entanto, cessassem), mas os ingleses buscaram aproximar-se dos mercadores de escravos que, do Brasil, aportavam na Costa da Mina. ${ }^{43}$ Os agentes da WIC (West-Indische Compagnie) e da RAC (Royal African Company), assim como de mercadores privados, foram instruídos a vender escravos e mercadorias aos luso-brasileiros na Costa da Mina como estratégia para obter o ouro do Brasil, o que se tornou um intercâmbio regular a partir dos anos $1720 .^{44}$

A intensidade deste comércio de ouro do Brasil em troca de fazendas e escravos ofertados pelos negreiros europeus deixou múltiplos indícios, tais como a denúncia feita por uma autoridade de São Tomé, endereçada ao rei, que afirmava que os navios estrangeiros que passavam pela ilha levavam para suas terras 5 a 7 arrobas de ouro "português", e que, para isso, segundo os próprios capitães dos negreiros britânicos, traziam duas carregações: uma para adquirir escravos e vendê-los aos portugueses por 6 a 9 onças de ouro, outra para comprar escravos e levá-los a Barbados e Martinica. ${ }^{45} \mathrm{Na}$ prática, a escolha por uma das duas opções dependia das circunstâncias. Humphry Morice, principal traficante de Londres na primeira metade do setecentos, além de dirigente do Banco da Inglaterra e membro do Parlamento, claramente preferia a primeira. Dos oito diários de bordo sobreviventes de Morice, sete contém instruções explícitas a seus capitães para que tentassem trocar todos os escravos que conseguissem em suas transações iniciais por ouro com portugueses. Se realizadas com sucesso, os capitães deveriam retornar com todo o ouro direto para Londres. ${ }^{46}$ Trocar todos os escravos por ouro, tal como sonhado pelo traficante inglês, no entanto, era complicado. A maioria das transações envolvia um pequeno número de escravos, como nas realizadas pelo capitão do Anne, que vendeu 14 escravos por 98 onças de ouro e 22 escravos por 170 onças e 12 ackies de ouro para, respectivamente, Manoel Fernandes Bastos e Antônio Nunes, capitães de navios negreiros oriundos da Bahia. ${ }^{47}$

Referências ao ouro do Brasil são também abundantes na documentação da RAC. Agentes da companhia se envolveram no comércio com portugueses tanto na África quanto no Brasil, ocasionalmente investindo conjuntamente nas mesmas viagens. $\mathrm{O}$ volume dessas relações trans-imperiais se tornou tão significativo que logo passou a gerar tensões na esfera pública britânica, sendo mobilizado, por exemplo, nos debates em torno do monopólio da RAC. Em outros momentos, a questão foi levantada pelo Board of Trade, com traficantes independentes, membros da companhia e donos de plantation no Caribe sendo chamados para 
opinar a respeito das vantagens e desvantagens do comércio de escravos anglo-português. Para a maioria dos observadores, o comércio de escravos com portugueses deveria se restringir à Costa da África, onde o acesso ao ouro se daria de modo mais seguro do que com desembarques ilegais no Brasil (e alguns navios foram, de fato, apreendidos por tentativas de contrabando na colônia ao longo do XVIII). ${ }^{48}$

Da mesma forma, holandeses estabeleceram múltiplas estratégias para acessar o ouro do Brasil que era carregado por portugueses para a Costa da Mina. Stuart Schwartz e Johannes Postma descrevem Brasil e Holanda como "parceiros comerciais" na África Ocidental setecentista. Diretores da WIC instruíram seus agentes, em diversos momentos na primeira metade do XVIII, a estabelecerem relações comerciais com os portugueses com o objetivo explícito de acessar o ouro. ${ }^{49}$ Holandeses competiam com ingleses em suas relações com portugueses, rivalidade que era agravada pela ainda pouco conhecida presença francesa. Quando um dos agentes da RAC requisitou às autoridades de Uidá o controle do fornecimento de escravos aos portugueses, com o argumento de que, assim, os preços se estabilizariam, o diretor do forte francês na região rapidamente interveio, sugerindo que a verdadeira intenção do inglês era monopolizar as importações de ouro. A proposta foi, consequentemente, negada ${ }^{50}$ Em princípios da década de 1750 , até mesmo traficantes dinamarqueses competiam pelo ouro do Brasil que chegava com os portugueses na região. Em uma carta aos diretores da West India and Guinea Company, em Copenhagen, o governador do forte de Christiansborg sugeria que a companhia investisse em um novo forte em Quitta (Keta) pois "não apenas conseguiriam realizar trocas com os portugueses, o que já seria de grande benefício para a Nobre Companhia diante do fato que eles compram escravos com ouro, mas, além disso, supostamente no sentido de que eles retirariam a maioria dos portugueses de suas relações com os holandeses, pois o português com o qual trocamos bens disse que o faria, e nos garantiu que muitos outros seguiriam o seu exemplo." 51

A despeito das rivalidades entre diferentes poderes europeus, parte do ouro do Brasil ficou na própria África Ocidental. Não possuímos estimativas do ouro que permaneceu na África, mas há alguns indícios de que seu volume não foi insignificante. Governantes locais de Alada, Uidá e, posteriormente, do Daomé demandaram ouro como pagamento de taxas portuárias e em troca de cativos, o que envolvia a participação de autoridades/mercadores sob a jurisdição daqueles poderes, responsáveis pela venda dos escravizados aos europeus. ${ }^{52}$ Assim, os luso-brasileiros tiveram acesso aos melhores cativos da região, que, não por acaso, passaram a ser designados de gold slaves e Portuguese slaves, o que, por sua vez, levou ao 
aumento dos seus preços. ${ }^{53}$ A ascensão do Daomé, em especial, foi marcada pelo contato direto entre autoridades africanas e comerciantes portugueses, eliminando o papel de intermediários que britânicos e outros europeus vinham exercendo em Uidá. Enquanto portugueses acessavam os melhores cativos, outros traficantes enfrentavam crescentes dificuldades para completar seus carregamentos. Tal disparidade ajuda a entender a discrepância entre o baixo número de rebeliões escravas a bordo de navios negreiros portugueses e sua maior frequência em embarcações do noroeste europeu na Baixa Guiné, como argumentou recentemente David Eltis. A demora nas operações do tráfico entre os concorrentes dos portugueses tornava tais expedições mais suscetíveis à resistência escrava, cujas ocorrências se davam majoritariamente no período de carregamento na costa ou pouco após o início das viagens para as Américas. ${ }^{54}$

Parte do ouro que chegava em Uidá era usada para contratar exércitos de mercenários em conflitos locais. Como observa Robin Law, no entanto, o ouro que chegava à região não ficava apenas nas mãos de reis e chefes, mas se difundia por toda a sociedade. Essa demanda difusa pelo ouro devia-se ao seu pequeno porte e grande valor, o que permitia que fosse guardado e carregado com grande facilidade em um contexto no qual migrações decorrentes de conflitos políticos eram uma possibilidade latente. No Daomé, apesar dos indícios de uso do ouro como ornamento, é muito possível que essa demanda difusa na sociedade fosse também fruto dessa facilidade de armazenamento e transporte. Na Costa do Ouro, cujas exportações de ouro vinham sendo substituídas por exportações de escravos em princípios do XVIII, o ouro continuava tendo papel fundamental como moeda, sendo usado no pagamento de exércitos, em processos cotidianos como a cobrança impostos e multas, e, especialmente no caso dos Axante, como sinal de riqueza e status, com um valor simbólico único que estimulava o uso de ornamentos de ouro em diferentes situações sociais. Judith Spicksley enfatiza esse papel simbólico do ouro entre os Axante como um possível elemento explicativo para a queda nas exportações do metal amarelo, mas reconhece que o contexto de guerra possivelmente teve um impacto sobre a produção local. Nesse sentido, parte do ouro do Brasil certamente atendeu a essa demanda, já que portugueses foram responsáveis pelo embarque de mais de 35.000 africanos escravizados na região no primeiro quarto do século XVIII (em sua grande maioria com destino a Pernambuco). ${ }^{55}$ 


\section{As estimativas dos fluxos de ouro do Brasil para a Costa da Mina}

Qual foi o volume de ouro do Brasil carregado para a Costa da Mina? Nunca teremos uma resposta exata para essa pergunta, mas o mergulho em parte da documentação existente permite tanto a construção de estimativas quanto um novo olhar sobre as impressões deixadas por contemporâneos. Em uma das poucas passagens na qual trata dos fluxos de ouro para a África, Noya Pinto, baseado em Verger, nota que há um grande número de referências na documentação da RAC sobre o ouro do Brasil na primeira metade dos anos 1720, precisamente quando as minas baianas de Jacobina e Rio das Contas estavam em seu auge produtivo. "Como o comércio com a África estava nas mãos de mercadores da Bahia," argumenta o autor, "pode-se inferir a vultosa corrente de ouro contrabandeado para aquele continente e que em seguida tomava o rumo da Europa". ${ }^{56}$ As minas baianas são deixadas de lado por Noya Pinto em função da ausência de documentos que permitissem uma quantificação mais cuidadosa. Isso o leva a abandonar, também, a discussão sobre os fluxos de ouro para a África no restante de sua obra. Mas alguns pontos merecem ser discutidos aqui. Em primeiro lugar, apesar da profusão de referências à RAC coletadas por Verger para a primeira metade dos anos 1720, a questão do ouro brasileiro permaneceu recorrente na documentação não apenas de britânicos, mas também de holandeses e de outros poderes na África Ocidental durante o segundo quarto do século. Certamente não foi apenas o ouro das minas baianas que, como vimos, alimentou um vasto comércio anglo-português de escravos na África. Além disso, importantes rotas internas levaram ao desembarque de um número significativo desses escravos nas próprias Minas Gerais, situação na qual o ouro mineiro foi moeda de troca. ${ }^{57}$ Finalmente, nem todo o ouro chegado à África foi redirecionado para a Europa. Parte ficou na própria África, com implicações importantes para a história de zonas específicas da região, como discutido anteriormente. ${ }^{58}$

Há pelo menos seis estimativas coevas do volume de ouro brasileiro que chegou à África Ocidental na primeira metade do setecentos. Em seu relato de viagem à Costa da Guiné, o britânico James Houston, cirurgião-chefe da RAC, argumentou que além dos 40.000 ounces de ouro que chegavam do interior à Costa do Ouro por meio dos próprios africanos, "25 ou 30000 ounces a mais são trazidos da costa do Brasil pelos portugueses para comprar escravos, e de lá carregados por mãos europeias para diferentes partes da Europa, veja-se Inglaterra, Holanda e França." 59 Se convertermos esse valores, temos a estimativa de que traficantes carregaram entre 709 e 850 quilos de ouro para a África em 1722, ano de início do 
relato de Houstoun. Philip Curtin, por sua vez, menciona a estimativa de um governador do Brasil, em 1721, de que algo em torno de 500.000 cruzados em ouro foram enviados à África, o equivalente a $478 \mathrm{~kg}$ do metal amarelo. Nesse mesmo período, o governador de Minas Gerais, Pedro Miguel de Almeida Portugal, o Conde de Assumar, estimava que 24 arrobas $(353 \mathrm{~kg}$ ) de ouro eram carregadas anualmente para a Costa da Mina - 12 embarcações por ano com 2 arrobas de ouro cada. ${ }^{60} \mathrm{Em} \mathrm{1750,} \mathrm{um} \mathrm{observador} \mathrm{francês} \mathrm{notava} \mathrm{que} \mathrm{algo} \mathrm{entre} 12$ e 15 navios saídos do Brasil chegavam anualmente em Uidá, cada um deles geralmente carregando entre 50 e 60 marcos de ouro, o equivalente a aproximadamente 168 quilos de ouro por ano. ${ }^{61}$ Finalmente, Roquinaldo Ferreira localizou duas estimativas para a primeira metade do XVIII. Uma delas, de 1721, em uma carta do Vice-Rei e Governador Geral do Brasil, aponta para a exportação de 90 arrobas, ou $1.323 \mathrm{~kg}$, de ouro. Na segunda, de 1728, comerciantes lisboetas escrevem que navios saindo da Bahia e de Pernambuco estariam carregando em torno de 100 arrobas, ou 1470 quilos, de ouro para a África Ocidental anualmente. ${ }^{62}$

Historiadores têm olhado com ceticismo para os altos números oferecidos por contemporâneos, não sem razão. Essas fontes, no geral, tendem a inflar os números com diferentes finalidades. No caso de James Houstoun, por exemplo, boa parte de sua narrativa visava convencer os britânicos da enorme lucratividade existente no comércio africano e da necessidade de se investir na sobrevivência da RAC. "Diga quem cava as ricas minas do Perú e Brasil, etc? Ou melhor, quem adoça o chá das senhoras," provocava Houstoun, "e quem ganha os lucros disso tudo? Consequentemente, deixe cada verdadeiro britânico unanimemente se juntar para pensar medidas, de como concentrar esse comércio tão vantajoso na Inglaterra; e gostaria que fosse conduzido pela RAC, que até aqui tem sido mais perdedora do que ganhadora por conta dele."63 Jaime Cortesão, por sua vez, em sua análise dos números oferecidos pelo Conde de Assumar, acredita que Martinho de Mendonça, enviado posteriormente pela Coroa para avaliar as dimensões do contrabando, estava mais próximo da realidade ao afirmar que o volume de ouro carregado para a África era pequeno. Finalmente, os comerciantes de Lisboa, como nota Ferreira, também parecem exagerar ao postular o carregamento de 100 arrobas de ouro anualmente entre o Nordeste do Brasil e a África Ocidental. ${ }^{64}$

Uma das poucas tentativas de estimativa do volume de ouro carregado do Brasil para a África na historiografia mais recente veio com Philip Curtin, que, baseado nos pagamentos de taxas para os holandeses em Elmina, estima que o volume médio de carregamentos de ouro em navios saídos do Brasil foi de 40 quilos entre 1718 e 1723 . Ferreira considera a estimativa 
de Curtin mais realista e a contrasta com números de Russell-Wood para a produção média de ouro no Brasil entre 1700 e 1729, que teria sido de 1.200 quilos. Os dados apresentados por Russell-Wood no texto citado, no entanto, são os mesmos de Noya Pinto. Para o quinquênio 1726-1729, a média anual é de 8.500 quilos, o que tornam menos absurdos os números apresentados pelas fontes coevas citadas por Ferreira e outros. ${ }^{65}$ Jaime Cortesão, por sua vez, confia mais no ceticismo de Mendonça com base no fato de que o governador do Rio de Janeiro, no ano seguinte ao relato de Mendonça, mandara prender os capitães de dois navios em Cabo Verde, acusados de transportarem ouro para ingleses em Cacheu e franceses na Gâmbia. O principal destino do ouro, como vimos, no entanto, era a Costa da Mina, com abundantes referências ao recebimento de ouro do Brasil por parte de ingleses, holandeses e outros europeus na região.

A estimativa de $40 \mathrm{~kg}$ por ano para o período 1718-1721 oferecida por Curtin, portanto, nos parece excessivamente conservadora ${ }^{66}$. O cálculo de Curtin, feito com base em um estudo de David Henige e Marion Johnson, é realizado a partir da taxa de $10 \%$ que os holandeses passaram a cobrar com mais vigor dos navios portugueses, em princípios do século XVIII. De acordo com os autores, no ano de 1721 os holandeses coletaram 41 marcos (pouco mais de $9 \mathrm{~kg}$ de ouro), o que implicaria em uma importação total de 400 marcos (ou aproximadamente $90 \mathrm{~kg}$ de ouro). Os autores, no entanto, consideram o ano de 1721 excepcional, argumentando que o maior volume de ouro naquele momento pode ter sido produto da construção do forte de Uidá e da presença de José Torres, um grande contrabandista de ouro na região. Há pelo menos dois motivos para não tratarmos o ano de 1721 como excepcional. Primeiro, a atuação de Torres, como demonstra Roquinaldo Ferreira, se estendeu ainda por alguns anos até o comerciante cair em ruína. Em segundo lugar, e mais importante, é precisamente em torno desse momento que o volume do ouro extraído de Minas Gerais começará a atingir números inéditos, o que se refletirá em picos inéditos nos números de cativos traficados a partir da África Ocidental (gráfico 1). Entre março de 1724 e março de 1727, por exemplo, o forte britânico em Uidá coletou 5.845 onças de ouro (166 kg), uma média de 55 quilos por ano. Se considerarmos que os fortes holandeses, especialmente Elmina, tinham fluxos tão ou mais volumosos de ouro do que os vizinhos britânicos, o ano de 1721 aparece como menos excepcional do que pensado por Henige e Johnson. Infelizmente, não temos o número de navios taxados para o ano de 1721, mas é muito provável que o número tenha se aproximado ao do ano seguinte (considerando que o total de viagens existentes na Voyages é o mesmo), quando 22 navios tiveram que pagar o imposto de $10 \%{ }^{67}$ 
Assim, a média de ouro carregado por navio no ano de 1721, que acreditamos ser bem menos excepcional do que colocam Henige e Johnson, foi de aproximadamente $4 \mathrm{~kg}$.

O número, ainda assim, nos parece muito baixo. Nesse período, o preço do escravo estava entre 5 e 6 ounces de ouro, o que equivalia a algo entre 140 e 170 gramas do metal nobre. Assim, a média de $4 \mathrm{~kg}$ de ouro permitiria a compra de 23 a 28 escravos. Vimos capitães portugueses comprando números muito próximos disso com Morice, como Antônio Nunes, que comprou 22 cativos por 170 onças e 12 ackies $^{68}$ de ouro. A compra dos escravos de Morice por Nunes, no entanto, foi apenas uma das várias trocas realizadas por ele, até que se completasse o número pretendido de cativos. Antônio Nunes comprou um total de 453 cativos antes de retornar à Bahia. Nos parece improvável que todo o ouro carregado por Nunes tenha sido gasto unicamente com os 22 escravos adquiridos do traficante de Morice, e os outros 431 com tabaco e outros produtos da terra. ${ }^{69}$

A média de escravos embarcados por navio no período entre 1722 e 1750 foi de 345 pessoas. Se considerarmos a possibilidade de que a maioria desses escravos foi comprada com ouro, como mais de um observador indica (e vimos vários exemplos nesse sentido na seção anterior), então chegaremos a uma estimativa bem menos conservadora do volume de ouro carregado para a África Ocidental. Um capitão português, João Baptista Rolhano, informou que navios da Bahia costumavam comprar escravos de holandeses por 6 a 7 onças de ouro cada e que, além disso, compravam mais de dois terços de todos os cativos com ouro, o mesmo que faziam os comerciantes de Pernambuco e do Rio de Janeiro (neste último caso, em proporções ainda maiores por não terem tabaco). ${ }^{70}$ No ano de 1733 , traficantes portugueses a bordo do Santana saíram de Lisboa para Uidá e contrataram agentes da RAC para que estes fornecessem 200 escravos, prometendo pagar três quartos dos cativos com ouro. $^{71}$ A estimativa de dois terços parece, portanto, razoável (e a indicação de que escravos estavam sendo comprados por 6 a 7 onças de ouro é confirmada por várias outras fontes do período). ${ }^{72}$ Se dois terços da média de 345 escravos (230) estavam sendo comprados com ouro a 6 ounces cada, temos que cada navio saído do Brasil carregava algo em torno de 1.380 ounces de ouro, ou $39 \mathrm{~kg}$. Esse número é próximo do oferecido pelo Conde de Assumar, que afirmava que cada navio saído da Bahia para a Costa da Mina carregava "ao menos duas arrobas de ouro em pó para o resgate dos negros que importam." ${ }^{\text {73 }}$ De acordo com o governador de Minas Gerais, portanto, no mínimo $29 \mathrm{~kg}$ de ouro em pó eram carregados pelos navios saídos da Bahia, volume mais próximo dos $39 \mathrm{~kg}$ que propusemos para as estimativas da Tabela 1. Os números mais altos nos parecem mais convincentes pois não apenas se 
Tabela 1: Número de expedições negreiras portuguesas para a África Ocidental, de navios taxados, de navios capturados pelos holandeses e estimativa anual de ouro carregado, 1722-1740

\begin{tabular}{|c|c|c|c|c|c|}
\hline Ano & Viagens & Ouro $(\mathrm{kg})$ & Ano & Viagens & Ouro $(\mathrm{kg})$ \\
\hline 1700 & 24 & 936 & 1726 & 41 & 1.599 \\
\hline 1701 & 21 & 819 & 1727 & 38 & 1.482 \\
\hline 1702 & 24 & 936 & 1728 & 31 & 1.209 \\
\hline 1703 & 24 & 936 & 1729 & 32 & 1.248 \\
\hline 1704 & 18 & 702 & 1730 & 21 & 819 \\
\hline 1705 & 16 & 624 & 1731 & 35 & 1.365 \\
\hline 1706 & 22 & 858 & 1732 & 18 & 702 \\
\hline 1707 & 34 & 1.326 & 1733 & 24 & 936 \\
\hline 1708 & 20 & 780 & 1734 & 25 & 975 \\
\hline 1709 & 25 & 975 & 1735 & 26 & 1.014 \\
\hline 1710 & 17 & 663 & 1736 & 13 & 507 \\
\hline 1711 & 24 & 936 & 1737 & 15 & 585 \\
\hline 1712 & 23 & 897 & 1738 & 18 & 702 \\
\hline 1713 & 29 & 1.131 & 1739 & 11 & 429 \\
\hline 1714 & 23 & 897 & 1740 & 21 & 819 \\
\hline 1715 & 29 & 1.131 & 1741 & 8 & 312 \\
\hline 1716 & 26 & 1.014 & 1742 & 27 & 1.053 \\
\hline 1717 & 17 & 663 & 1743 & 6 & 234 \\
\hline 1718 & 22 & 858 & 1744 & 21 & 819 \\
\hline 1719 & 27 & 1.053 & 1745 & 8 & 312 \\
\hline 1720 & 32 & 1.248 & 1746 & 15 & 585 \\
\hline 1721 & 32 & 1.248 & 1747 & 22 & 858 \\
\hline 1722 & 32 & 1248 & 1748 & 19 & 741 \\
\hline 1723 & 24 & 936 & 1749 & 17 & 663 \\
\hline 1724 & 52 & 2.028 & 1750 & 15 & 585 \\
\hline 1725 & 40 & 1.560 & Total & 1.204 & 46.956 \\
\hline
\end{tabular}

Utilizamos a média de $39 \mathrm{~kg}$ de ouro por navio e multiplicamos pelo número de viagens. Fonte: http://slavevoyages.org/voyages/I71Zpp4o 
aproximam das várias estimativas oferecidas por observadores coevos, a despeito de todos os seus problemas, mas estão em sintonia com a abundância de referências ao ouro do Brasil que aparece na documentação britânica e holandesa. O valor total de aproximadamente $47.000 \mathrm{~kg}$ de ouro para todo o período entre 1701 e 1750 nos parece razoável ${ }^{74}$. De acordo com as estimativas de Noya Pinto, o total de ouro extraído no Brasil durante esse mesmo período foi de $428.335 \mathrm{~kg}$. Todo esse ouro, em sua maior parte saído de Minas Gerais, era extraído por escravos africanos. Escravos eram trocados por ouro na costa da África, carregados para Minas Gerais, onde extraíam mais ouro para ser trocado por mais escravos, alimentando um ciclo que atingiria o seu auge em meados do setecentos. Não deveria surpreender, portanto, que uma parte significativa do ouro fosse destinado a alimentar as fontes de trabalho escravizado que, antes de tudo, tornavam possível a circulação daquele mesmo ouro.

\section{Considerações finais}

A despeito dos debates e revisões acerca dos possíveis efeitos do fluxo de ouro do Brasil para a Europa na primeira metade do Setecentos, há muito que a historiografia tem demonstrado que o maior beneficiário dessa injeção inaudita de metal amarelo foi a economia inglesa por meio de suas relações mercantis com Portugal. ${ }^{75} \mathrm{O}$ foco dessa bibliografia, como vimos, recaiu sobre a rota que conectou Brasil, Portugal e Grã-Bretanha. Enquanto, em termos numéricos, esse foi o caminho mais importante do ouro do Brasil, a rota africana teve papel fundamental na conformação do trato negreiro na Costa da Mina (que foi, por sua vez, central para a própria extração do ouro e constituição da rota Brasil-Portugal) e nas possibilidades de acesso abertas a outros impérios europeus. No caso aqui discutido, pode-se dizer que houve maior multiplicidade de beneficiários no comércio de ouro que ligou alguns portos do Brasil à Costa da Mina. Não apenas ingleses, mas holandeses, franceses e dinamarqueses, além dos súditos do Daomé e de outras sociedades africanas, puseram as mãos nos aques e ounces de ouro que os tratistas luso-brasileiros carrearam para aquelas paragens, embora, evidentemente, o quinhão de cada um daqueles tenha sido desigual. Ainda que na Europa, àquela altura, o ouro brasileiro seguisse para outras praças além de Londres, na Costa da Mina, o destino do ouro foi mais desconcentrado, em parte por causa da ausência de um intermediário monopolista, pois a região era um mercado aberto a todos os europeus que buscavam comprar cativos.

Dada a importância do ouro para o tráfico português na Costa da Mina e as inúmeras 
referências ao metal precioso na documentação produzida por traficantes de diferentes origens, é fundamental reconsiderar a questão básica em torno de qual foi o volume que foi deslocado para a África Ocidental. Nesse sentido, o total de $47.000 \mathrm{~kg}$ de ouro carregados para a África, equivalente a pouco mais de $10 \%$ de todo o ouro extraído do Brasil durante a primeira metade do setecentos, não nos parece irrealista. Foi esse ouro que permitiu a compra de parte significativa dos escravos que extrairiam mais ouro, uma mercadoria chave que permitiu que luso-brasileiros consolidassem efetivamente a sua presença na Costa da Mina e conduzissem o trato negreiro de modo mais estável que outros impérios europeus naquela região. Uma de suas consequências mais óbvias foi o embarque de mais de 425.000 africanos escravizados com destino ao Brasil, em grande medida empregados na mineração do ouro ou nas inúmeras atividades que por ela foram estimuladas por todo o espaço colonial.

Enquanto o ouro que permanecia na África alimentou a consolidação de reinos como o do Daomé, estreitando os laços com traficantes portugueses e dando estabilidade ao comércio, o volume desconhecido que seguiu para a Europa contribuiu, combinado com as enormes quantias que seguiam direto do Brasil para Portugal e, de lá, para a Grã-Bretanha, para importantes transformações no continente. No caso da Grã-Bretanha, a construção do estado fiscal-militar, bem como os investimentos produtivos e comerciais em geral (incluindo em seus espaços escravistas no Caribe), dependeu do estabelecimento de um ambiente financeiro estável, para o qual o ouro do Brasil contribuiu significativamente. Conforme estabelecia o padrão-ouro em sua economia, a Grã-Bretanha fechava seus circuitos comerciais na Ásia com parte da prata que era drenada da América espanhola por outros meios (que incluía o tráfico de escravos). Parte do ouro também seguiu para a Ásia, principalmente para a Índia, cujos tecidos também eram amplamente consumidos por todo o Atlântico. Dessa forma, por meios diretos e indiretos, o ouro do Brasil contribuiu para o incremento das trocas globais e a construção da hegemonia britânica no sistema capitalista mundial. A via africana foi um importante elo desse conjunto de transformações.

\section{Notas}

\footnotetext{
${ }^{1}$ BOXER, C. R. The golden age of Brazil, 1695-1750: growing pains of a colonial society. Berkeley: University of California Press, 1962, p. 59-60; PINTO, Virgílio Noya. O ouro brasileiro e o comércio anglo-português: uma contribuição dos estudosda economia atlântica no século XVIII. 2. ed. São Paulo: Ed. Nacional, 1979; MORINEAU, Michel. Incroyables gazettes et fabuleux métaux: les retours des trésors américains d'après les gazettes hollandaises (XVIe-XVIIIe siècles). London; New York: Paris: Cambridge University Press ; Maison
} 
des sciences de l'homme, 1985. Para uma discussão dos dados de Noya Pinto e Morineau, ver CARRARA, Angelo Alves. La producción de oro en Brasil, siglo XVIII. In: HAUSBERGER, BERND; IBARRA, ANTONIO (Org.). Oro y plata en los inicios de la economía global: de las minas a la moneda. Centro de estudios históricos. Primera edición. ed. México, D.F.: El Colegio de México, 2014.

2 FISHER, Harold Edward Stephen. The Portugal trade: a study of Anglo-Portuguese commerce, 1700-1770. London: Methuen, 1971; SIDERI, S. Comércio e poder: colonialismo informal nas relações anglo-portuguesas. Lisboa: Cosmos, 1978; MAXWELL, Kenneth. The Atlantic in the Eighteenth Century: A Southern Perspective on the Need to Return to the "Big Picture". Transactions of the Royal Historical Society, v. 3, p. 209-236, 1993, p. 219; BOXER, Charles R. "Brazilian Gold and British Traders in the First Half of the Eighteenth Century." The Hispanic American Historical Review, vol. 49, no. 3, 1969, pp. 459, 462, 465, 470.

${ }^{3}$ CUNHA, D. Luís da. Instruções Políticas. Lisboa: CNCDP, 2001, p. 348 e 372.

${ }^{4}$ Portugal ainda importava, segundo Maria João Ferreira, quantidades consideráveis de tecidos da Índia ao final do séc. XVII; FERREIRA, Maria João Ferreira, "Asian Textiles in the Carreira da India: Portuguese Trade, Consumption and Taste, 1500-1700", Textile History, 46, 2, novembre 2015, p. 147-168. No XVIII, parte do abastecimento do comércio português no Atlântico devia-se às escalas ou arribadas que as naus da Índia faziam no Brasil e em Angola; FERREIRA, Roquinaldo. Dinâmica do comércio intracolonial: geribitas, panos asiáticos e guerra no tráfico angolano de escravos, século XVIII. In: FRAGOSO, JOÃO LUÍS RIBEIRO; BICALHO, MARIA FERNANDA; GOUVÊA, MARIA DE FÁTIMA (Org.). . O Antigo Regime nos trópicos: a dinâmica imperial portuguesa, séculos XVI-XVIII. Rio de Janeiro: Civilização Brasileira, 2001. p. 339-78; LAPA, José Roberto do Amaral. A Bahia e a Carreira da Índia. Ed. facs ed. São Paulo: Editora Hucitec Editora Da Unicamp, 2000. (Coleção Estudos Históricos, 42). Um documento significativo a respeito é a "Lista das Fazendas que se despacharam na alfândega desta cidade [Luanda]", que começa em 1766. Arquivo Histórico Ultramarino (AHU), Lisboa, Angola, Cx. 50, doc. 16. Despachos de outras naus da Índia em Luanda: AHU, Angola, cx.51, doc. 71, 20/05/1767; AHU, Angola, cx. 55, doc. 53, 12/08/1771; AHU, Angola, cx. 56, doc. 70, 30/06/1772. Sobre o comércio anglo-português na primeira metade do séc. XVIII, no qual os têxteis predominavam amplamente, cf. FISHER, The Portugal Trade, p. 2, 8-9, 11-2. Sobre a produção manufatureira portuguesa, MACEDO, Jorge B. de. Problemas de historia da indústria portuguesa no Século XVIII. 2. ed. Lisboa: Querco, 1982, especialmente p. 61-121; PEDREIRA, Jorge Miguel Viana. Estrutura industrial $e$ mercado colonial: Portugal e Brasil (1780-1830). Lisboa: DIFEL, 1994, especialmente p. 65-137. Para uma discussão sobre diferentes estimativas do ouro na Grã-Bretanha, cf. RICHARDSON, David; EVANS, E.W. Empire and Accumulation in Eighteenth-Century Britain. In: BROTHERSTONE, TERRY; PILLING, GEOFFREY (Org.). . History, economic history and the future of Marxism: essays in memory of Tom Kemp (1921-1993). London: Porcupine, 1996.

5 PINTO, O ouro brasileiro, pp. 84-5. Quando discute o tráfico de escravos, Pinto, seguindo os passos de Verger, coloca o tabaco no centro. Cf. pp. 200-1; FISHER, The Portugal Trade, caps. 1 e 9; EBERT, Christopher. From Gold to Manioc: Contraband Trade in Brazil during the Golden Age, 1700-1750. Colonial Latin American Review, v. 20, n. 1, p. 109-130, 1 abr. 2011; COSTA, Leonor Freire; ROCHA, Maria Manuela; SOUSA, Rita Martins De. O ouro do Brasil. Lisboa: Imprensa Nacional-Casa da Moeda, 2013.

${ }^{6}$ ANTONIL, André João. Cultura e Opulência do Brasil. [1711]. 3ª. ed. Belo Horizonte; São Paulo: Itatiaia; Edusp, 1982; CALDAS, José Antonio. Notícia Geral de toda esta Capitania da Bahia desde o seu descobrimento até o presente ano de 1759. [Salvador]: Beneditina, 1951. (Ed. fac-similar]; MENDES, Antonio de Oliveira. Discurso Preliminar, Histórico, Introdutório, com Natureza de Descrição Econômica da Comarca e Cidade da Bahia. In: Anais da Biblioteca Nacional do Rio de Janeiro, vol. XXVII. Rio de Janeiro: BN, 1906, p. 283-348; INFORMAÇÃO Geral da Capitania de Pernambuco. Annaes da Bibliotheca Nacional do Rio de Janeiro, vol. XXVIII, 1906, p. 117-496. (Ed. original 1749). Há certa imprecisão quanto à que região correspondiam os portos aos quais os luso-brasileiros denominavam de Costa da Mina. Em termos gerais, seus limites geográficos compreendiam desde o cabo do Monte até o de Lopo Gonçalves, o que englobaria desde a Costa do Ouro até a Baía de Biafra. Na prática, porém, os portugueses não traficavam por toda esta extensão (ao menos, não na mesma intensidade). Quando afirmavam que iam ou vinham da Costa da Mina, referiam-se aos portos situados entre o rio Volta e o rio Lagos, compreendendo a região que os ingleses chamavam "Costa dos Escravos", ou à "sotavento da Mina", como prefere Pierre Verger, e a baía do Benin, incluindo os portos de Offra e Uidá (a que os portugueses denominavam Ajudá), os dois mais importantes, nos séculos XVII e XVIII, respectivamente. GOULART, Maurício. A Escravidão Africana no Brasil. (Das origens à extinção do tráfico). 2a. ed. São Paulo: Martins Fontes, 1950, p. 186; VERGER, Pierre F. Fluxo e Refluxo do Tráfico de Escravos entre o Golfo de Benin e a Bahia de Todos os Santos: dos séculos XVII a XIX. Salvador: Corrupio, 1987, p. 37 e ss; CURTIN, Philip D. The Atlantic Slave Trade: A Census. Madison: University of Wisconsin Press, 1972, p. 
129-30; cf. também MANNING, Patrick. The Slave Trade in the Bight of Benin, 1640-1890. In: GEMERY, Henry A.; HOGENDORN, Jan S. (Ed.). The Uncommon Market. Essays in the Economic History of Atlantic Slave Trade. Nova York: Academic Press, 1979, p. 107-41, p. 107, 114-5. Apesar da centralidade de Uidá no comércio da região, a importância dos demais portos variou ao longo do século XVIII e no XIX; cf. SILVA JR, Carlos F. da, "Interações atlânticas entre Salvador e Porto Novo (Costa da Mina) no século XVIII", Revista de História, (São Paulo), n.176, 2017.

${ }^{7}$ VIANA FILHO, Luiz. O Negro na Bahia. $3^{\text {a }}$. ed. Rio de Janeiro: Nova Fronteira, 1988; GOULART, Maurício. A Escravidão Africana no Brasil; VERGER, Pierre F. Fluxo e Refluxo; SOARES, Mariza de Carvalho. Indícios para o traçado das rotas terrestres de escravos na Baía de Benim, Século XVIII. In. Idem (Org.). Rotas Atlânticas da Diáspora Africana: da Baía de Benim ao Rio de Janeiro. Niterói, RJ: EdUFF, 2007, p. 65-94; MANNING, "The Slave Trade in the Bight of Benin"; LAW, Robin. "Ethnicities of Enslaved Africans in the Diaspora: On the Meanings of "Mina" (Again)". History in Africa, n. 32, 2005, p. 247-267; SANTOS, Corcino Medeiros dos. A Bahia no comércio português da Costa da Mina e a concorrência estrangeira. In: SILVA, Maria Beatriz Nizza da. (Org.). Brasil: Colonização e Escravidão. Rio de Janeiro: Nova Fronteira, 2000, p. 221-38.

${ }^{8}$ LAW, Robin. The Gold Trade of Whydah in the Seventeenth and Eighteenth centuries. In: HENIGE, DAVID P.; MCCASKIE, T. C. (Org.). . West African Economic and Social History: Essays in Memory of Marion Johnson. [S.1.]: African Studies Program, University of Wisconsin-Madison, 1990. p. 105-18; SPICKSLEY, Judith. Pawns on the Gold Coast: the Rise of the Asante and the Shifts in Security for Debt, 1680-1750. The Journal of African History, v. 54, n. 2, p. 147-175, jul. 2013. Agradecemos a Carlos Silva Jr. por nos chamar a atenção para esta referência.

${ }^{9}$ GODINHO, Vitorino de Magalhaes. Descobrimentos e a economia mundial. Lisboa: Arcadia, 1963.

${ }^{10}$ BARRETT, Ward. World bullion flows, 1450-1800. In: TRACY, JAMES D. (Org.). . The Rise of merchant empires: long-distance trade in the early modern world, 1350-1750. Studies in comparative Early Modern History. Cambridge; New York: Cambridge University Press, 1990.

11 FLYNN, Dennis O.; GIRÁLDEZ, Arturo. Born with a "Silver Spoon": The Origin of World Trade in 1571. Journal of World History, v. 6, n. 2, p. 201-221, 1 out. 1995.

12 MIELANTS, Eric. Early Modern Antwerp: The First "World City"? Journal of Historical Sociology, v. 30, n. 2, p. 262-283, 1 jun. 2017; MOORE, Jason W. Silver, Ecology, and the Origins of the Modern World, 14501640. In: HORNBORG, ALF; MCNEILL, JOHN ROBERT; ALIER, JUAN MARTÍNEZ (Org.). Rethinking Environmental History: World-system History and Global Environmental Change. Lanham: Rowman Altamira, 2007.

13 ROMANO, Ruggiero. Conjonctures opposées: la "crise" du XVIIe siècle en Europe et en Amérique ibérique. [S.1.]: Librairie Droz, 1992. Há uma edição em espanhol.

${ }^{14}$ MARQUESE, Rafael Bivar. "Economia escravista mundial”. In: SCHWARCZ, Lilia Moritz; GOMES, Flávio dos Santos (Org.). Dicionário da escravidão e liberdade: 50 textos críticos. São Paulo: Companhia das Letras, 2018; DUNN, Richard S. Sugar and slaves: the rise of the planter class in the English West Indies, 1624-1713. Chapel Hill: University of North Carolina Press, 1972.

15 Sobre a magnitude da produção aurífera do Brasil, além do clássico de PINTO, O Ouro brasileiro $e$ o Comércio Anglo-Português, cf. a revisão quantitativa de TEPASKE, John J. A New World of Gold and Silver. Leiden, Brill, 2010, p. 27-50, que revisa os dados disponíveis considerando as pesquisas de Michel Morineau, Incroyable gazettes et fabuleux métaux, segundo o qual o volume de ouro saído do Brasil foi ainda maior do que se estimara; no entanto, as pesquisas de COSTA, ROCHA e SOUZA levantam argumentos convincentes contra as estimativas de remessas de ouro do Brasil para o reino apresentadas por Morineau, sobretudo a fiabilidade dos dados hauridos nas gazetas holandesas; COSTA, ROCHA, SOUSA, O Ouro do Brasil, p. 51-9.

${ }^{16}$ Ver GALLOWAY, J. H., "Nordeste do Brasil, 1700-1750. Reexame de uma crise". Revista Brasileira de Geografia. Rio de Janeiro, 36 (2), p. 85-102, abril/junho, 1974 e SCHWARTZ, Stuart B. Segredos Internos: engenhos e escravos na sociedade colonial. São Paulo: Companhia das Letras, 1988, p. 165-9, a despeito da discordância entre os autores quanto ao início da crise.

17 ELTIS, David. Economic Growth and the Ending of the Transatlantic Slave Trade. Nova York: Oxford University Press, 1997, p. 247; FLORENTINO, Manolo. Em costas negras. Uma história do tráfico entre a África e o Rio de Janeiro. São Paulo: Companhia das Letras, 1997, p. 64-9.

${ }^{18}$ FURTADO, Celso. Formação Econômica do Brasil. 25ª. Ed. São Paulo: Cia. Editora Nacional, 1995, p. 75-7; CARRARA, Ângelo Alves. Minas e Currais: produção rural e mercado interno em Minas Gerais, 1674-1807. Juiz de Fora, MG: UFJF, 2007, p. 113-136; as procurações entre diversos agentes mercantis demonstram, igualmente, essa conexão entre os diversos espaços da América portuguesa; cf. MATHIAS, Carlos Leonardo 
Kelmer. As Múltiplas Faces da Escravidão: O espaço econômico do ouro e sua elite pluriocupacional na formação da sociedade mineira setecentista, c. 1711- c. 1756. Rio de Janeiro: Mauad, 2012, p. 105-59.

19 ELTIS, Economic Growth, p. 34-37; ELTIS, David; RICHARDSON, David. "A New Assessment of the Atlantic Slave Trade". In: ELTIS; RICHARDSON (Org.) Extending the Frontiers. Essays on the New TransAtlantic Slave Trade Database. New Haven: Yale University Press, 2008, p. 26-7, 31-32. Sobre as alterações na hierarquia dos portos do Brasil: LOPES, Gustavo Acioli. A fênix e o Atlântico: a capitania de Pernambuco e a economia-mundo europeia. São Paulo: Alameda, 2018 e CARRARA, Ângelo Alves. Minas e Currais, p. 119-23, que utilizam dados dos contratos de arrecadação de direitos sobre a importação de escravos. Quanto aos números de cativos importados, ELTIS, RICHARDSON, "A New Assessment"..

${ }^{20}$ Para o período 1701-1760, os embarques no Golfo de Benin são superiores aos de Angola/Congo em cerca de 6\%; mas para 1701-1730, a diferença é de mais de 100\%. Todas as estimativas usadas no texto vêm de www.slavevoyages.org, exceto quanto notado.As estimativas para o Brasil, constantes desta base de dados, são explicadas em ELTIS, RICHARDSON, “A New Assessment”, p. 7-21.

21 BERGAD, Laird W. Escravidão e história econômica: demografia de Minas Gerais, 1720-1888. Bauru, SP: Editora da Universidade do Sagrado Coração, 2004, p. 46-50; SOARES, Carlos Eugênio Líbano; SILVA Jr., Carlos F. da, "Uma nova guiné": africanos em inventários e registros de batismo na cidade da Bahia da primeira metade do século XVIII", História Unisinos, 14(3): p. 242-256, Setembro/Dezembro 2010; como argumenta Mariza de Carvalho Soares, com base em dados para o Rio de Janeiro setecentista, a denominação "mina" oculta a diversidade étnica dos indivíduos escravizados e deportados pela Costa da Mina; SOARES, Introdução; Indícios para o traçado das Rotas Terrestres de Escravos na Baía do Benin, século XVIII, p. 13-26, 67-75. Sobre o sentido histórico da denominação "mina" e as etnias a ele relacionadas, ver LAW, Robin, "Ethnicities of enslaved africans in the diaspora: on the meanings of "Mina" (again)", History in Africa, 32 (2005), p. 247-26; HALL, Gwendolyn Midlo. Slavery and African Ethnicities in the Americas: Restoring The Links. Chapel Hill: University of North Carolina Press, 2005, p. 112-25.

${ }^{22}$ SOBRE a devaça q tirou o ouvidor geral da Ilha de S.Thomé Domingos Martins Quaresma do sargento Mayor Fernão Soares de Noronha. S. Tomé, 2 de agosto de 1683. AHU, CU, S. Tomé, Cx. 3, Doc. 66.

23 [REPRESENTAÇÃO do Senado da Câmara e homens bons da cidade e ilha de S. Tomé sobre o mau estado da ilha.]. S. Tomé, 4 de março de 1699. AHU, CU, S.Tomé, Cx. 3, D. 157.

${ }^{24}$ Carta do capitão mor da Paraíba, João de Abreu Castel Branco. 24 de dezembro de 1726. AHU, Paraíba, cx. doc. 6. Sobre o comércio de escravos a partir da Paraíba e Goiana, cf. LOPES, A Fênix e o Atlântico, p. 99, 1335. Agradecemos a Matheus Silveira Guimarães a indicação deste documento.

${ }^{25}$ Nardi e Verger supõem que a rota Brasil-Costa da Mina começou com a ocupação holandesa em Angola (1641-1648), enquanto outros autores afirmam que os indícios de sua regularidade são posteriores; NARDI, Jean-Baptiste. O fumo brasileiro no período colonial: lavoura, comércio e administração. São Paulo: Brasiliense, 1996, p. 215-7; VERGER, Fluxo e Refluxo, p. 24, 34, 56; cf. LAW, Robin. The Slave Coast of West Africa: 1550-1750. Oxford: Clarendon Press, 1991, p. 123, 157, 162. ELTIS \& RICHARDSON, "New Assessment", p. 18; ver, porém, LOPES, A Fênix e o Atlântico, p. 40-2, que cita uma carta de João Fernandes Vieira ao rei, de 1677, na qual se atesta o fluxo de embarcações negreiras de Lisboa e Pernambuco para a Costa da Mina.

${ }^{26}$ Cf. LAW, Robin, "The Slave Trade in Seventeenth-Century Allada: A Revision”. African Economic History, No. 22 (1994), pp. 59-92.

27 LOPES, A Fênix e o Atlântico, p. 49-58.

28 DAVIS, Ralph. La Europa Atlántica. Mexico: Siglo XXI, 1976, p. 274-88; BLACKBURN, Robin. A Construção do Escravismo no Novo Mundo: Do barroco ao moderno 1492-1800. Rio de Janeiro: Record, 2003, p. 451-554; SHAMMAS, Carole. "The revolutionary impact of European demand for tropical goods". In: MCCUSKER, John J.; MORGAN, Kenneth (org.). The Early Modern Atlantic Economy. Cambridge University Press, 2000, p. 163-85. Para uma abordagem recente sobre as origens da "sugar revolution" nas Antilhas, ver MCCUSKER, John J.; MENARD, Russel R. "The Sugar Industry in the Seventeenth Century: A New Perspective on the Barbadian 'Sugar Revolution"”. In: SCHWARTZ, Stuart B. (Org.) Tropical Babylons: Sugar and the Making of the Atlantic World, 1450-1680. University of Carolina Press, 2004, p. 289-330. Uma abordagem mais ampla sobre o papel econômico das colônias inglesas escravistas encontra-se em MENARD, Russell R., "Plantation Empire: How Sugar and Tobacco Planters Built their Industries and Raised an Empire", Agricultural History, Vol. 81, No. 3, 2007, pp. 309-332.

29 RAWLEY, James A. RAWLEY, James A. London, metropolis of the slave trade. Columbia: University of Missouri Press, 2003, p. 31-2; PETTIGREW, William A. Freedom's Debt: The Royal African Company and the 
Politics of the Atlantic Slave Trade, 1672-1752. Chapel Hill: University of North Carolina Press, 2014, p. 11-2, $32,37-8,44$.

${ }^{30}$ LAW, The Slave Coast of West Africa, p. 126-9, 133-4. LAW, Robin. Ouidah: The Social History of a West African Slaving Port, 1727-1892. Athens; Oxford: Ohio UP; James Currey, 2004, p. 31-6.

${ }^{31}$ LAW, Robin. The Slave Coast of West Africa, p. 152-3; LAW, Ouidah, p. 36. Alguns autores têm enfatizado a autonomia dos poderes locais frente aos agentes escravistas forâneos em África: FERREIRA, Roquinaldo, “A primeira partilha da África decadência e ressurgência do comércio português na Costa do Ouro (ca. 1637 - ca. 1700)", Varia Historia, Belo Horizonte, Vol. 26, nº 44, p. 479-498, jul/dez 2010; enquanto outros apontam os limites desta agência africana e distinguem seus efeitos de curto e longo prazo: INIKORI, J., "Ideology versus the Tyranny of Paradigm: Historians and the impact of the Atlantic Slave Trade on African Societies", African Economic History, n 22 , p. 37-58, 1994.

${ }^{32}$ Seguimos a distinção feita por Curtin entre competição mercantil e livre comércio; CURTIN, Philip. Cross Cultural Trade in World History. Londres: Cambridge UP, 1984, p. 32; sobre o impacto do comércio escravista na economia do Daomé e das áreas sob sua jurisdição, ver LAW, Ouidah, 44-5, 48-9. Sobre a diversidade e as mudanças nos padrões de demanda de importados na África atlântica, cf. METCALF, George, "A Microcosm of Why Africans sold Slaves: Akan Consumption Patterns in the 1770s", The Journal of African History, 28, p. 377-394; ALPERN, Stanley, "What Africans Got for Their Slaves: A Master List of European Trade Goods", History in Africa, 22, 1995, 5-43; RICHARDSON, David. West African Consumption Patterns and their Influence on the Eighteenth-Century English Slave Trade. In: GEMERY; HOGENDORN, (Ed.). The Uncommon Market. Essays in the Economic History of Atlantic Slave Trade. Nova York: Academic Press, 1979, p. 303-30; RUDERMAN, Anne Elizabeth. Supplying the Slave Trade: How Europeans met African Demand for European Manufactured Products, Commodities and Re-exports, 1670-1790. Connecticut: Tese de Doutorado, Yale University, 2016; KELLEY, Sean M. "New World Slave Traders and the Problem of Trade Goods: Brazil, Barbados, Cuba and North America in Comparative Perspective." The English Historical Review, v. 134, n. 567, p. 302-333, 12 jun. 2019.

33 ELTIS \& RICHARDSON, “A New Assessment”, p. 46-7.

${ }^{34}$ David Richardson, no entanto, demonstrou que a contribuição da baía do Benin neste período, em termos absolutos, foi menor do que Philip Curtin estimara. Para os dados de Curtin referentes às quatro primeiras décadas do século XVIII, Curtin, The Atlantic Slave Trade, p. 129, 150; revistos por Lovejoy, que os aceita com pequenas alterações, Paul Lovejoy. "The Volume of the Atlantic Slave Trade: a Synthesis". The Journal of African History, vol. 23, n. 4, 1982, p. 496. Sobre a revisão para cima, cf. Richardson, "The Eighteenth Century British Slave Trade", p. 168-9, 172-3; ELTIS, The Rise of African Slavery, p. 181-3; CURTIN, The Atlantic Slave Trade, p. 221-2; RICHARDSON, "The Eighteenth Century British Slave Trade: estimates of its volume and coastal distribution in Africa", Research in Economic History, Connecticut: Jai Press, vol. 12, 1989, p. 1724.

35 MANNING, Patrick. Slavery and African Life. Occidental, Oriental and African slave trade. Cambridge: Cambridge University Press, 1995, p. 130-1.

${ }^{36}$ ELTIS, David. The Rise of African Slavery in the Americas. Cambridge, U.K: Cambridge University Press, 2000, p. 166, 177-8, 181; Manning, Slavery and African Life, p. 133-4; Sobre as tendências das exportações da África atlântica a partir de fins do século XVII, ver ELTIS, David; JENNINGS, Lawrence C., "Trade between Western Africa and the Atlantic World in the Pre-Colonial Era", The American Historical Review, Vol. 93, No. 4 (Oct., 1988), pp. 936-959.

${ }^{37}$ Dados do TSTD, consulta em 20/05/2018; ver, ainda, os números propostos por RIBEIRO, Alexandre Vieira, "The Transatlantic Slave Trade to Bahia, 1582-1851". In: ELTIS, RICHARDSON, Extending the Frontiers, p. 132-134; e as críticas às estimativas de Verger, Nardi e Manning em LOPES, A Fênix e o Atlântico, p. 209-10.

${ }^{38}$ POSTMA, Johannes; SCHWARTZ, Stuart, "The Dutch Republic and Brazil as Commercial Partners on the West African Coast during the Eighteenth Century". In: POSTMA, J; ENTHOVEN, V. (org.). Riches from Atlantic Commerce. Dutch Transatlantic Trade and Shipping, 1585-1817. Leiden; Boston: Brill, p. 196.

${ }^{39}$ LAW, The Slave Coast of West Africa, p. 321-2; SILVA, Alberto da Costa E. Francisco Félix de Souza, mercador de escravos. Rio de Janeiro: EdUERJ : Nova Fronteira, 2004, p. 64-5.

40 Além dos clássicos de Viana Filho, O Negro na Bahia, e de VERGER, Fluxo e Refluxo, o tema foi aprofundado por NARDI, $O$ fumo brasileiro no período colonial; RIBEIRO, Alexandre Vieira. A cidade de Salvador: estrutura econômica, comércio de escravos, grupo mercantil (c.1750 - c.1800). Tese de Doutorado (História). Rio de Janeiro: UFRJ, 2009, p. 185-230 (embora numa perspectiva mais social); SILVA JR, Carlos F. "Tráfico, traficantes e agentes na Bahia setecentista", Salvador, Revista de História, 1, 1 (2009), pp. 37-52. Tema 
durante muito tempo quase ignorado, o estudo dos grupos mercantis no império português foi revitalizado por FRAGOSO, João Luís. Homens De Grossa Aventura: Acumulação E Hierarquia Na Praça Mercantil Do Rio De Janeiro, 1790-1830. 2a. ed. revista ed. Rio de Janeiro: Civilização Brasileira, 1998, cap. 4, especialmente; FLORENTINO, Em Costas Negras; para Lisboa, PEDREIRA, Jorge. "Tratos e contratos: actividades, interesses e orientações dos investimentos dos negociantes da praça de Lisboa (1755-1822)", Análise Social, Lisboa, vol. XXXI (136-137), 1996 ( $\left.2^{\circ} .3^{\circ}\right)$, p.355-379. Uma síntese abrangente, embora restrita ao séc. XVII, encontra-se em COSTA, Leonor Freire. Império e grupos mercantis: entre o Oriente e o Atlântico (século XVII). Lisboa: Horizonte, 2002. Há, ainda, o estudo clássico de FLORY, Rae; SMITH, David G., "Bahian Merchants and Planters in the Seventeenth and Early Eighteenth Centuries", The Hispanic American Historical Review, Vol. 58, No. 4 (Nov., 1978), p. 571-594.

41 Robin Law indica, com ressalvas, informações contemporâneas que trazem alguns números sobre as exportações de ouro do Brasil pelos franceses a partir da Costa da Mina. Cf. LAW, "The gold trade of Whydah", p.108. A crescente atuação francesa na Costa do Ouro, por exemplo, contribuiu para o enfraquecimento do comércio escravista a partir de Bristol. Ver MORGAN, Kenneth. Bristol and the Atlantic trade in the eighteenth century: Kenneth Morgan. Cambridge [England] ; New York, N.Y.: Cambridge University Press, 1993, p. 142.

${ }^{4}$ BOXER, Charles R. O Império Ultramarino Português. Lisboa: Edições 70, 2001, p. 126-7. Para um estudo detalhado das relações luso-holandesas na África Ocidental antes e depois da criação da WIC, ver RIBEIRO DA SILVA, Filipa. Dutch and Portuguese in Western Africa. Empires, Merchants and the Atlantic System, 15801674. Leiden: Brill, 2011, cap. 6.

${ }^{43}$ VERGER, Fluxo e Refluxo, p. 57-62; LOPES, A Fênix e o Atlântico, p. 70; STRICKRODT, Silke. AfroEuropean Trade in the Atlantic World: The Western Slave Coast, C.1550-c.1885. Oxford: James Currey, 2015, p. 115; POSTMA \& SCHWARTZ, "The Dutch Republic and Brazil", 171-99.

44 POSTMA, Johannes. The Dutch in the Atlantic Slave Trade, 1600-1815. Cambridge UP, 1990, p. 77-8; POSTMA \& SCHWARTZ, "The Dutch Republic and Brazil as Commercial Partners", p. 181-4, 188, 196; LAW, "The gold trade of Whydah", p. 106-7; RAWLEY, James A. London, Metropolis of the Slave Trade, p. 48, 53, 56; MARQUES, Leonardo, Um banqueiro-traficante inglês e a comércio interimperial de escravos no Atlântico Setecentista (1688-1732). In: MATHIAS, Carlos Leonardo Kelmer et all. Ramificações Ultramarinas: Sociedades Comerciais no Âmbito do Atlântico Luso. Rio de Janeiro: Mauá; FAPERJ, 2017, p. 88-9; MARQUES, Leonardo. "O Ouro Brasileiro e o Comércio Anglo-Português de Escravos." In História e Historiografia Do Trabalho Escravo No Brasil: Novas Perspectivas, edited by Henrique Ré, Laurent Saes, and Gustavo Velloso. São Paulo: Edusp, prelo.

${ }^{45}$ EXTRACTO das Contas q tenho dado a Sua Mag.de pello Tribunal do Concelho do Ultramar de q não veyo the agora resolussão. S. Tomé, 4 de abril de 1737. AHU, CU, S. Tomé, Cx. 6, Doc. 49.

${ }^{46}$ RAWLEY, James A. London, metropolis of the slave trade; MARQUES, "O ouro brasileiro".

${ }^{47}$ Para as expedições dos dois negreiros baianos, ver as viagens 50592 e 50574 em www.slavevoyages.org; MARQUES, "O ouro brasileiro e o comércio anglo-português de escravos".

48 MARQUES, "O ouro brasileiro e o comércio anglo-português de escravos", prelo; PIJNING, Ernst. Regulating Illegal Trade: Foreign Vessels in Brazilian Harbors. Portuguese Studies Review, v. 15, n. 1/2, p. 32166, 2007.

49 POSTMA \& SCHWARTZ, "The Dutch Republic and Brazil”, p. 190.

${ }^{50}$ LAW, "The Gold Trade of Whydah," p. 108.

51 JUSTESEN, Ole; MANLEY, James (Org.). Danish sources for the history of Ghana, 1657-1754. Copenhagen: Det Kongelige Danske Videnskabernes Selskab, 2005, p. 813.

52 LAW, The Slave Coast of West Africa, p. 109-10; LAW, Robin. "Royal Monopoly and Private Enterprise in the Atlantic Trade: The Case of Dahomey". The Journal of African History, vol. 18, n. 4, 1977, p. 555-77; vários oficiais foram estabelecidos pelos governantes para o negócio com os europeus nos portos escravistas, como o "yevogan" ou "capitão dos brancos": LAW, Ouidah, p. 43, 55, 57, 123. O papel dos agentes mercantis africanos, em outros contextos, é destacado por SPARKS, Randy. Where the Negroes Are Masters. Cambridge: Harvard UP, 2014, p. 35 e ss.; MILLER, Joseph Calder. Way of death: merchant capitalism and the Angolan slave trade, 1730-1830. Madison, Wis.: University of Wisconsin Press, 1988, p. 207-44; MARTIN, Phyllis. O comércio externo da costa do Loango, 1576-1870: o impacto das mudanças comerciais no reino Vili do Loango. Luanda: Arquivo Nacional de Angola, Ministério da Cultura, 2010, p. 127-54.

53 LAW, "The gold trade of Whydah", p. 107; LAW, The Slave Coast of West Africa, p. 107, 109-10. O papel do ouro no tráfico da Costa da Mina a partir de Pernambuco é enfatizado, também, por SILVA, Daniel Domingues da, ELTIS, David, “The Slave Trade to Pernambuco, 1561-1851”. In: ELTIS, David; RICHARDSON, David 
(Org.). Extending the Frontiers: Essays on the New Transatlantic Slave Database. New Haven: Yale University Press, 2008, p. 120. Para um exemplo de uma embarcação de Pernambuco traficando nos vários portos da Costa da Mina, embora a documentação pareça escamotear a presença do ouro, temos a [ENTRADA da Carregaçam que no Recife de Pernambuco me consignou o Sr. Jozé de Freitas Sacotto, na sua galera por invocação Aleluya da Surreição e Almas; a mim Jozé Francisco Rocha]. Costa da Mina, 1752. AHU, CU, S. Tomé, Cx. 8, Doc. 100. Ver, ainda, LOPES, A Fênix e o Atlântico, p. 166 e ss.

54 ELTIS, David. "Iberian Dominance and the Intrusion of the Northern Europeans into the Atlantic World: Slave Trading as a Result of Economic Growth?" Almanack, prelo.

55 LAW, "The Gold Trade of Whydah"; SPICKSLEY, "Pawns on the Gold Coast"; SILVA JR., Carlos Da. Slave Trade, African Ethnicities and Cultural Exchanges between Bahia and the Bight of Benin, 1721-1817. Tese de Doutorado, University of Hull, Hull, 2019.

${ }^{56}$ PINTO, O ouro brasileiro, pp. 85-6.

${ }^{57}$ FURTADO, Júnia Ferreira. Teias de Negócio: conexões mercantis entre as minas do ouro e a Bahia durante o século XVIII. In: FRAGOSO, JOÃO LUÍS RIBEIRO; FLORENTINO, MANOLO; SAMPAIO, ANTONIO CARLOS JUCÁ DE (Org.). Nas rotas do Império: eixos mercantis, tráfico e relações sociais no mundo português. Vitória: EDUFES, 2006.

${ }^{58}$ Sobre o ouro na África, ver CURTIN, Philip D. Africa and the Wider Monetary World, 1250-1850. In:

RICHARDS, J. F. (Org.). . Precious metals in the later medieval and early modern worlds. Durham, N.C.: Carolina Academic Press, 1983. p. 231-268.

${ }^{59}$ HOUSTOUN, James. Some new and accurate observations geographical, natural and historical. Containing a true and impartial account of the situation, product, and natural history of the coast of Guinea, ... By James Houstoun. London: Printed for JPeele, 1725, p. 25

${ }^{60}$ CORTESÃO, Jaime. Alexandre de Gusmão \& O tratado de Madrid. São Paulo: Imprensa Oficial Fundação Alexandre de Gusmão, 2006, p. 56.

${ }^{61}$ LAW, "The Gold Trade of Whydah", p. 111. Law oferece a mesma estimativa em libras (370).

62 FERREIRA, Roquinaldo. "From Brazil to West Africa: Dutch-Portuguese rivalry, gold-smuggling, and African politics in the Bight of Benin." In: GROESEN, MICHIEL VAN (Org.). . The legacy of Dutch Brazil. New York, NY: Cambridge University Press, 2014, p. 92.

63 HOUSTON, Some new and accurate observations, p. 44.

64 CORTESÃO, Alexandre de Gusmão, p. 57.

65 FERREIRA, "From Brazil to West Africa", p. 92.

66 Nesse tema, mais uma vez, constata-se a tendência de Curtin a considerar superestimados os dados quantitativos contemporâneos relativos ao comércio atlântico escravista; cf. INIKORI, Joseph E. "Measuring the Atlantic Slave Trade: a Rejoinder", The Journal of African History, Cambridge University Press, Vol. 17, n 4, p. 613-4, 1976; MBOKOLO, Elikia. África negra: história e civilizações. Vol. 1: O Séc. XVIII. Lisboa: Colibri, 2007 , p. 323 , onde o autor afirma que Curtin inaugura a "escola minimalista" da historiografia do tráfico de escravos; BARRY, Boubacar. Senegambia and the Atlantic slave trade. Cambridge: CUP, 1998, p. 39 e ss.

${ }^{67}$ Postma \& Schwartz, "The Dutch Republic and Brazil", p. 181.

${ }^{68}$ Um ackie equivalia a 1/16 de um onça de ouro. Sobre o ounce ou onça e os ackies como unidades de conta na Costa do Ouro e na Costa dos Escravos, cf. JOHNSON, Marion, "The Ounce in Eighteenth-Century West African Trade", The Journal of African History, Vol. 7, No. 2 (1966), pp. 197-214; HOGENDORN, Jan; JOHNSON, Marion The Shell Money of the Slave Trade. Cambridge: CUP, 1986, p. 134.

${ }_{70}^{69}$ Ver a viagem de número 50574 em slavevoyages.org.

70 LOPES, Edmundo Correia. A Escravatura: subsídios para a sua história. Lisboa: Editorial Atica, 1944, p. 119; ACIOLI e MENZ, Resgate e Mercadorias, p. 60.

71 Sobre o Santana, ver a viagem de número 49404 em www.slavevoyages.org. Hall to RAC, James Fort, 1733.06.05, T70/4,74.

72 Ao final da década de 1720, o diretor do forte inglês em Uidá informava que os preços dos melhores cativos ia de 5 e 1/2 a 7 onças; Thomas Wilson to Franklin, Reed and Peake, Uidá, 24 de fevereiro de 1727; Thomas Wilson to Franklin, Reed and Peake, Uidá, 12 de julho de 1728. In: LAW, Robin (org.). Correspondence of the Royal African Company. Madison: University of Wisconsin, 1991, p. 19-20, 36. No entanto, caso os portugueses comprassem os escravos dos demais negreiros europeus, os preços variavam de 6 a 9 onças de ouro por cativo. [CARTA do governador de S. Tomé Serafim Teixeira Sarmento ao rei D. João V]. S. Tomé, [Ant. 13 de 
Novembro de 1731]. AHU, CU, S. Tomé, cx. 5, doc. 88; EXTRACTO das Contas q tenho dado a Sua Mag.de pello Tribunal do Concelho do Ultramar de q não veyo the agora resolussão. S. Tomé, 4 de abril de 1737. AHU, CU, S. Tomé, cx. 6, doc. 49.

73 CORTESÃO, Alexandre de Gusmão, p. 56.

74 Ficaríamos, ainda assim, bem abaixo da média apontada por um mercador de escravos com grande experiência na Costa da Mina, José de Torres, que dizia, no início dos anos 1720, que se exportavam 150 arrobas (ou $2.250 \mathrm{Kg}$ ) de ouro por ano do Brasil para a África; [CONSULTA do Conselho Ultramarino sobre a representação de José de Torres]. Lisboa, Post. 2 de novembro de 1721. AHU, CU, S. Tomé, cx. 4, doc. 85. Sobre as peripécias e o contrabando realizado por José de Torres, cf. VERGER, Fluxo e Refluxo, p. 152-9, 1724; Roquinaldo Ferreira, "Biografia, Mobilidade e Cultura Atlântica: A Micro-Escala do Tráfico de Escravos em Benguela, séculos XVIII-XIX”. Revista Tempo, Niterói, 2006, p. 39 e ss..

75 Além dos textos de Boxer, Sideri e Fisher, já citados, cf. INIKORI, Joseph E. Africans and the Industrial Revolution in England. Cambridge University Press, 2002, p. 413-5. PALMA, Nuno, "Anglo-Portuguese Trade And Monetary Transmission During the Eighteenth Century", Nova School of Business and Economics. Draft: October 21, 2012.

\section{Referências Bibliográficas}

ALPERN, Stanley, "What Africans Got for Their Slaves: A Master List of European Trade Goods", History in Africa, 22, 1995, 5-43.

ANTONIL, André João. Cultura e Opulência do Brasil. [1711]. 3ª . ed. Belo Horizonte; São Paulo: Itatiaia; Edusp, 1982.

BARRETT, Ward. World bullion flows, 1450-1800. In: TRACY, JAMES D. (Org.). . The Rise of merchant empires: long-distance trade in the early modern world, 1350-1750. Studies in comparative Early Modern History. Cambridge; New York: Cambridge University Press, 1990.

BARRY, Boubacar. Senegambia and the Atlantic slave trade. Cambridge: CUP, 1998.

BERGAD, Laird W. Escravidão e história econômica: demografia de Minas Gerais, 17201888. Bauru, SP: Editora da Universidade do Sagrado Coração, 2004.

BLACKBURN, Robin. A Construção do Escravismo no Novo Mundo: Do barroco ao moderno 1492-1800. Rio de Janeiro: Record, 2003.

BOXER, C. R. The golden age of Brazil, 1695-1750: growing pains of a colonial society. Berkeley: University of California Press, 1962.

BOXER, Charles R. "Brazilian Gold and British Traders in the First Half of the Eighteenth Century." The Hispanic American Historical Review, vol. 49, no. 3, 1969.

BOXER, Charles R. O Império Ultramarino Português. Lisboa: Edições 70, 2001.

CALDAS, José Antonio. Notícia Geral de toda esta Capitania da Bahia desde o seu descobrimento até o presente ano de 1759. [Salvador]: Beneditina, 1951. 
CARRARA, Ângelo Alves. Minas e Currais: produção rural e mercado interno em Minas Gerais, 1674-1807. Juiz de Fora, MG: UFJF, 2007.

CARRARA, Angelo Alves. La producción de oro en Brasil, siglo XVIII. In: HAUSBERGER, BERND; CORTESÃO, Jaime. Alexandre de Gusmão \& O tratado de Madrid. São Paulo: Imprensa Oficial Fundação Alexandre de Gusmão, 2006.

COSTA, Leonor Freire. Império e grupos mercantis: entre o Oriente e o Atlântico (século XVII). Lisboa: Horizonte, 2002.

COSTA, Leonor Freire; ROCHA, Maria Manuela; SOUSA, Rita Martins De. O ouro do Brasil. Lisboa: Imprensa Nacional-Casa da Moeda, 2013.

CUNHA, D. Luís da. Instruções Políticas. Lisboa: CNCDP, 2001.

IBARRA, ANTONIO (Org.). Oro y plata en los inicios de la economía global: de las minas a la moneda. Centro de estudios históricos. Primera edición. ed. México, D.F.: El Colegio de México, 2014.

CURTIN, Philip D. The Atlantic Slave Trade: A Census. Madison: University of Wisconsin Press, 1972.

CURTIN, Philip D. Africa and the Wider Monetary World, 1250-1850. In: RICHARDS, J. F. (Org.). . Precious metals in the later medieval and early modern worlds. Durham, N.C.: Carolina Academic Press, 1983. p. 231-268.

CURTIN, Philip. Cross Cultural Trade in World History. Londres: Cambridge UP, 1984.

DAVIS, Ralph. La Europa Atlántica. Mexico: Siglo XXI, 1976.

DUNN, Richard S. Sugar and slaves: the rise of the planter class in the English West Indies, 1624-1713. Chapel Hill: University of North Carolina Press, 1972.

EBERT, Christopher. From Gold to Manioc: Contraband Trade in Brazil during the Golden Age, 1700-1750. Colonial Latin American Review, v. 20, n. 1, p. 109-130, 1 abr. 2011.

ELTIS, David. Economic Growth and the Ending of the Transatlantic Slave Trade. Nova York: Oxford University Press, 1997.

ELTIS, David. The Rise of African Slavery in the Americas. Cambridge, U.K: Cambridge University Press, 2000.

ELTIS, David. Iberian Dominance and the Intrusion of the Northern Europeans into the Atlantic World: Slave Trading as a Result of Economic Growth? Almanack, n. 22, p. 496550, ago. 2019.

ELTIS, David; RICHARDSON, David. “A New Assessment of the Atlantic Slave Trade”. In: 
ELTIS; RICHARDSON (Org.) Extending the Frontiers. Essays on the New Trans-Atlantic Slave Trade Database. New Haven: Yale University Press, 2008.

ELTIS, David; JENNINGS, Lawrence C., "Trade between Western Africa and the Atlantic World in the Pre-Colonial Era", The American Historical Review, Vol. 93, No. 4 (Oct., 1988), pp. 936-959.

FERREIRA, Maria João Ferreira, "Asian Textiles in the Carreira da India: Portuguese Trade, Consumption and Taste, 1500-1700”, Textile History, 46, 2, novembre 2015, p. 147-168.

FERREIRA, Roquinaldo. Dinâmica do comércio intracolonial: geribitas, panos asiáticos e guerra no tráfico angolano de escravos, século XVIII. In: FRAGOSO, JOÃO LUÍS RIBEIRO;

BICALHO, MARIA FERNANDA; GOUVÊA, MARIA DE FÁTIMA (Org.). . o Antigo Regime nos trópicos: a dinâmica imperial portuguesa, séculos XVI-XVIII. Rio de Janeiro: Civilização Brasileira, 2001. p. 339-78.

FERREIRA, Roquinaldo. "Biografia, Mobilidade e Cultura Atlântica: A Micro-Escala do Tráfico de Escravos em Benguela, séculos XVIII-XIX”. Revista Tempo, Niterói, 2006.

FERREIRA, Roquinaldo, "A primeira partilha da África decadência e ressurgência do comércio português na Costa do Ouro (ca. 1637 - ca. 1700)", Varia Historia, Belo Horizonte, Vol. 26, nº 44, p. 479-498, jul/dez 2010.

FERREIRA, Roquinaldo. "From Brazil to West Africa: Dutch-Portuguese rivalry, goldsmuggling, and African politics in the Bight of Benin." In: GROESEN, MICHIEL VAN (Org.). . The legacy of Dutch Brazil. New York, NY: Cambridge University Press, 2014.

FISHER, Harold Edward Stephen. The Portugal trade: a study of Anglo-Portuguese commerce, 1700-1770. London: Methuen, 1971.

FLORENTINO, Manolo. Em costas negras. Uma história do tráfico entre a África e o Rio de Janeiro. São Paulo: Companhia das Letras, 1997.

FLORY, Rae; SMITH, David G., "Bahian Merchants and Planters in the Seventeenth and Early Eighteenth Centuries", The Hispanic American Historical Review, Vol. 58, No. 4 (Nov., 1978), p. 571-594.

FLYNN, Dennis O.; GIRÁLDEZ, Arturo. Born with a "Silver Spoon": The Origin of World Trade in 1571. Journal of World History, v. 6, n. 2, p. 201-221, 1 out. 1995.

FRAGOSO, João Luís. Homens De Grossa Aventura: Acumulação E Hierarquia Na Praça Mercantil Do Rio De Janeiro, 1790-1830. 2a. ed. revista ed. Rio de Janeiro: Civilização Brasileira, 1998.

FURTADO, Celso. Formação Econômica do Brasil. 25a . Ed. São Paulo: Cia. Editora Nacional, 1995. 
FURTADO, Júnia Ferreira. Teias de Negócio: conexões mercantis entre as minas do ouro e a Bahia durante o século XVIII. In: FRAGOSO, JOÃO LUÍS RIBEIRO; FLORENTINO, MANOLO; SAMPAIO, ANTONIO CARLOS JUCÁ DE (Org.). Nas rotas do Império: eixos mercantis, tráfico e relações sociais no mundo português. Vitória: EDUFES, 2006.

GALLOWAY, J. H., "Nordeste do Brasil, 1700-1750. Reexame de uma crise". Revista Brasileira de Geografia. Rio de Janeiro, 36 (2), p. 85-102, abril/junho, 1974.

GODINHO, Vitorino de Magalhaes. Descobrimentos e a economia mundial. Lisboa: Arcadia, 1963.

GOULART, Maurício. A Escravidão Africana no Brasil. (Das origens à extinção do tráfico). 2a. ed. São Paulo: Martins Fontes, 1950.

HALL, Gwendolyn Midlo. Slavery and African Ethnicities in the Americas: Restoring The Links. Chapel Hill: University of North Carolina Press, 2005.

HOGENDORN, Jan; JOHNSON, Marion The Shell Money of the Slave Trade. Cambridge: CUP, 1986.

HOUSTOUN, James. Some new and accurate observations geographical, natural and historical. Containing a true and impartial account of the situation, product, and natural history of the coast of Guinea, ... By James Houstoun. London: Printed for JPeele, 1725.

INIKORI, Joseph E. "Measuring the Atlantic Slave Trade: a Rejoinder", The Journal of African History, Cambridge University Press, Vol. 17, n 4, p. 613-4, 1976.

INIKORI, J., "Ideology versus the Tyranny of Paradigm: Historians and the impact of the Atlantic Slave Trade on African Societies", African Economic History, n 22, p. 37-58, 1994.

INIKORI, Joseph E. Africans and the Industrial Revolution in England. Cambridge University Press, 2002.

JOHNSON, Marion, "The Ounce in Eighteenth-Century West African Trade", The Journal of African History, Vol. 7, No. 2 (1966), pp. 197-214

JUSTESEN, Ole; MANLEY, James (Org.). Danish sources for the history of Ghana, 16571754. Copenhagen: Det Kongelige Danske Videnskabernes Selskab, 2005.

KELLEY, Sean M. "New World Slave Traders and the Problem of Trade Goods: Brazil, Barbados, Cuba and North America in Comparative Perspective." The English Historical Review, v. 134, n. 567, p. 302-333, 12 jun. 2019.

LAPA, José Roberto do Amaral. A Bahia e a Carreira da Índia. Ed. facs ed. São Paulo: Editora Hucitec Editora Da Unicamp, 2000.

LAW, Robin. "Royal Monopoly and Private Enterprise in the Atlantic Trade: The Case of Dahomey". The Journal of African History, vol. 18, n. 4, 1977. 
LAW, Robin. The Gold Trade of Whydah in the Seventeenth and Eighteenth centuries. In: HENIGE, DAVID P.; MCCASKIE, T. C. (Org.). West African Economic and Social History: Essays in Memory of Marion Johnson. [S.1.]: African Studies Program, University of Wisconsin-Madison, 1990. p. 105-18.

LAW, Robin (org.). Correspondence of the Royal African Company. Madison: University of Wisconsin, 1991

LAW, Robin, "The Slave Trade in Seventeenth-Century Allada: A Revision". African Economic History, No. 22 (1994), pp. 59-92.

LAW, Robin. The Slave Coast of West Africa: 1550-1750. Oxford: Clarendon Press, 1991

LAW, Robin. Ouidah: The Social History of a West African Slaving Port, 1727-1892. Athens; Oxford: Ohio UP; James Currey, 2004.

LAW, Robin. "Ethnicities of Enslaved Africans in the Diaspora: On the Meanings of "Mina" (Again)". History in Africa, n. 32, 2005, p. 247-267.

LOPES, Edmundo Correia. A Escravatura: subsídios para a sua história. Lisboa: Editorial Atica, 1944.

LOPES, Gustavo Acioli. A fênix e o Atlântico: a capitania de Pernambuco e a economiamundo europeia. São Paulo: Alameda, 2018

LOVEJOY, Paul. "The Volume of the Atlantic Slave Trade: a Synthesis". The Journal of African History, vol. 23, n. 4, 1982.

MACEDO, Jorge B. de. Problemas de historia da indústria portuguesa no Século XVIII. 2. ed. Lisboa: Querco, 1982.

MANNING, Patrick. The Slave Trade in the Bight of Benin, 1640-1890. In: GEMERY, Henry A.; HOGENDORN, Jan S. (Ed.). The Uncommon Market. Essays in the Economic History of Atlantic Slave Trade. Nova York: Academic Press, 1979, p. 107-41.

MANNING, Patrick. Slavery and African Life. Occidental, Oriental and African slave trade. Cambridge: Cambridge University Press, 1995.

MARQUES, Leonardo, Um banqueiro-traficante inglês e a comércio interimperial de escravos no Atlântico Setecentista (1688-1732). In: MATHIAS, Carlos Leonardo Kelmer et all. Ramificações Ultramarinas: Sociedades Comerciais no Âmbito do Atlântico Luso. Rio de Janeiro: Mauá; FAPERJ, 2017, p. 88-9;

MARQUES, Leonardo. "O Ouro Brasileiro e o Comércio Anglo-Português de Escravos." In História e Historiografia Do Trabalho Escravo No Brasil: Novas Perspectivas, edited by Henrique Ré, Laurent Saes, and Gustavo Velloso. São Paulo: Edusp, prelo. 
MARQUESE, Rafael Bivar. "Economia escravista mundial”. In: SCHWARCZ, Lilia Moritz; GOMES, Flávio dos Santos (Org.). Dicionário da escravidão e liberdade: 50 textos críticos. São Paulo: Companhia das Letras, 2018.

MARTIN, Phyllis. O comércio externo da costa do Loango, 1576-1870: o impacto das mudanças comerciais no reino Vili do Loango. Luanda: Arquivo Nacional de Angola, Ministério da Cultura, 2010.

MATHIAS, Carlos Leonardo Kelmer. As Múltiplas Faces da Escravidão: O espaço econômico do ouro e sua elite pluriocupacional na formação da sociedade mineira setecentista, c. 1711- c. 1756. Rio de Janeiro: Mauad, 2012.

MAXWELL, Kenneth. The Atlantic in the Eighteenth Century: A Southern Perspective on the Need to Return to the "Big Picture". Transactions of the Royal Historical Society, v. 3, p. 209-236, 1993.

MBOKOLO, Elikia. África negra: história e civilizações. Vol. 1: O Séc. XVIII. Lisboa: Colibri, 2007.

MCCUSKER, John J.; MENARD, Russel R. "The Sugar Industry in the Seventeenth Century: A New Perspective on the Barbadian 'Sugar Revolution"'. In: SCHWARTZ, Stuart B. (Org.) Tropical Babylons: Sugar and the Making of the Atlantic World, 1450-1680. University of Carolina Press, 2004, p. 289-330.

MENARD, Russell R., "Plantation Empire: How Sugar and Tobacco Planters Built their Industries and Raised an Empire", Agricultural History, Vol. 81, No. 3, 2007, pp. 309-332.

MENDES, Antonio de Oliveira. Discurso Preliminar, Histórico, Introdutório, com Natureza de Descrição Econômica da Comarca e Cidade da Bahia. In: Anais da Biblioteca Nacional do Rio de Janeiro, vol. XXVII. Rio de Janeiro: BN, 1906, p. 283-348.

METCALF, George, "A Microcosm of Why Africans sold Slaves: Akan Consumption Patterns in the 1770s", The Journal of African History, 28, p. 377-394.

MIELANTS, Eric. Early Modern Antwerp: The First "World City"? Journal of Historical Sociology, v. 30, n. 2, p. 262-283, 1 jun. 2017

MILLER, Joseph Calder. Way of death: merchant capitalism and the Angolan slave trade, 1730-1830. Madison, Wis.: University of Wisconsin Press, 1988.

MOORE, Jason W. Silver, Ecology, and the Origins of the Modern World, 1450-1640. In: HORNBORG, ALF; MCNEILL, JOHN ROBERT; ALIER, JUAN MARTÍNEZ (Org.). Rethinking Environmental History: World-system History and Global Environmental Change. Lanham: Rowman Altamira, 2007.

MORGAN, Kenneth. Bristol and the Atlantic trade in the eighteenth century: Kenneth Morgan. Cambridge [England] ; New York, N.Y.: Cambridge University Press, 1993. 
MORINEAU, Michel. Incroyables gazettes et fabuleux métaux: les retours des trésors américains d'après les gazettes hollandaises (XVIe-XVIIIe siècles). London; New York: Paris: Cambridge University Press ; Maison des sciences de l'homme, 1985.

NARDI, Jean-Baptiste. O fumo brasileiro no período colonial: lavoura, comércio e administração. São Paulo: Brasiliense, 1996

PALMA, Nuno, "Anglo-Portuguese Trade And Monetary Transmission During the Eighteenth Century”, Nova School of Business and Economics. Draft: October 21, 2012.

PEDREIRA, Jorge. "Tratos e contratos: actividades, interesses e orientações dos investimentos dos negociantes da praça de Lisboa (1755-1822)”, Análise Social, Lisboa, vol. XXXI (136-137), $1996\left(2^{\circ} .3^{\circ}\right)$, p.355-379.

PEDREIRA, Jorge Miguel Viana. Estrutura industrial e mercado colonial: Portugal e Brasil (1780-1830). Lisboa: DIFEL, 1994.

PETTIGREW, William A. Freedom's Debt: The Royal African Company and the Politics of the Atlantic Slave Trade, 1672-1752. Chapel Hill: University of North Carolina Press, 2014.

PINTO, Virgílio Noya. O ouro brasileiro e o comércio anglo-português: uma contribuição dos estudosda economia atlântica no século XVIII. 2. ed. São Paulo: Ed. Nacional, 1979;

PIJNING, Ernst. Regulating Illegal Trade: Foreign Vessels in Brazilian Harbors. Portuguese Studies Review, v. 15, n. 1/2, p. 321-66, 2007.

POSTMA, Johannes. The Dutch in the Atlantic Slave Trade, 1600-1815. Cambridge UP, 1990.

POSTMA, Johannes; SCHWARTZ, Stuart, "The Dutch Republic and Brazil as Commercial Partners on the West African Coast during the Eighteenth Century". In: POSTMA, J;

ENTHOVEN, V. (org.). Riches from Atlantic Commerce. Dutch Transatlantic Trade and Shipping, 1585-1817. Leiden; Boston: Brill.

RAWLEY, James A. London, metropolis of the slave trade. Columbia: University of Missouri Press, 2003.

RIBEIRO, Alexandre Vieira. A cidade de Salvador: estrutura econômica, comércio de escravos, grupo mercantil (c.1750 - c.1800). Tese de Doutorado (História). Rio de Janeiro: UFRJ, 2009.

RIBEIRO, Alexandre Vieira, "The Transatlantic Slave Trade to Bahia, 1582-1851".In: ELTIS, David; RICHARDSON, David (Org.). Extending the Frontiers: Essays on the New Transatlantic Slave Database. New Haven: Yale University Press, 2008.

RIBEIRO DA SILVA, Filipa. Dutch and Portuguese in Western Africa. Empires, Merchants and the Atlantic System, 1580-1674. Leiden: Brill, 2011. 
RICHARDSON, David. West African Consumption Patterns and their Influence on the Eighteenth-Century English Slave Trade. In: GEMERY; HOGENDORN, (Ed.). The Uncommon Market. Essays in the Economic History of Atlantic Slave Trade. Nova York: Academic Press, 1979, p. 303-30.

RICHARDSON, David. "The Eighteenth Century British Slave Trade: estimates of its volume and coastal distribution in Africa", Research in Economic History, Connecticut: Jai Press, vol. $12,1989$.

RICHARDSON, David; EVANS, E.W. Empire and Accumulation in Eighteenth-Century Britain. In: BROTHERSTONE, TERRY; PILLING, GEOFFREY (Org.). . History, economic history and the future of Marxism: essays in memory of Tom Kemp (1921-1993). London: Porcupine, 1996.

ROMANO, Ruggiero. Conjonctures opposées: la "crise" du XVIIe siècle en Europe et en Amérique ibérique. [S.1.]: Librairie Droz, 1992.

RUDERMAN, Anne Elizabeth. Supplying the Slave Trade: How Europeans met African Demand for European Manufactured Products, Commodities and Re-exports, 1670-1790. Connecticut: Tese de Doutorado, Yale University, 2016.

SANTOS, Corcino Medeiros dos. A Bahia no comércio português da Costa da Mina e a concorrência estrangeira. In: SILVA, Maria Beatriz Nizza da. (Org.). Brasil: Colonização e Escravidão. Rio de Janeiro: Nova Fronteira, 2000, p. 221-38.

SCHWARTZ, Stuart B. Segredos Internos: engenhos e escravos na sociedade colonial. São Paulo: Companhia das Letras, 1988.

SHAMMAS, Carole. "The revolutionary impact of European demand for tropical goods". In: MCCUSKER, John J.; MORGAN, Kenneth (org.). The Early Modern Atlantic Economy. Cambridge University Press, 2000, p. 163-85.

SIDERI, S. Comércio e poder: colonialismo informal nas relações anglo-portuguesas. Lisboa: Cosmos, 1978.

SILVA, Alberto da Costa E. Francisco Félix de Souza, mercador de escravos. Rio de Janeiro: EdUERJ : Nova Fronteira, 2004.

SILVA, Daniel Domingues da, ELTIS, David, "The Slave Trade to Pernambuco, 15611851”. In: ELTIS, David; RICHARDSON, David (Org.). Extending the Frontiers: Essays on the New Transatlantic Slave Database. New Haven: Yale University Press, 2008.

SILVA JR, Carlos F. "Tráfico, traficantes e agentes na Bahia setecentista", Salvador, Revista de História, 1, 1 (2009), pp. 37-52.

SILVA JR, Carlos F. da, "Interações atlânticas entre Salvador e Porto Novo (Costa da Mina) no século XVIII”, Revista de História, (São Paulo), n.176, 2017. 
SILVA JR., Carlos Da. Slave Trade, African Ethnicities and Cultural Exchanges between Bahia and the Bight of Benin, 1721-1817. Tese de Doutorado, University of Hull, Hull, 2019.

SOARES, Carlos Eugênio Líbano; SILVA Jr., Carlos F. da, "Uma nova guiné": africanos em inventários e registros de batismo na cidade da Bahia da primeira metade do século XVIII", História Unisinos, 14(3): p. 242-256, Setembro/Dezembro 2010.

SOARES, Mariza de Carvalho. Indícios para o traçado das rotas terrestres de escravos na Baía de Benim, Século XVIII. In. Idem (Org.). Rotas Atlânticas da Diáspora Africana: da Baía de Benim ao Rio de Janeiro. Niterói, RJ: EdUFF, 2007, p. 65-94.

SPARKS, Randy. Where the Negroes Are Masters. Cambridge: Harvard UP, 2014.

SPICKSLEY, Judith. Pawns on the Gold Coast: the Rise of the Asante and the Shifts in Security for Debt, 1680-1750. The Journal of African History, v. 54, n. 2, p. 147-175, jul. 2013.

STRICKRODT, Silke. Afro-European Trade in the Atlantic World: The Western Slave Coast, C.1550-c.1885. Oxford: James Currey, 2015.

TEPASKE, John J. A New World of Gold and Silver. Leiden, Brill, 2010.

VERGER, Pierre F. Fluxo e Refluxo do Tráfico de Escravos entre o Golfo de Benin e a Bahia de Todos os Santos: dos séculos XVII a XIX. Salvador: Corrupio, 1987.

VIANA FILHO, Luiz. O Negro na Bahia. $3^{\text {a }}$. ed. Rio de Janeiro: Nova Fronteira, 1988 